\title{
Receiver-operating characteristics of adiposity for metabolic syndrome: the Healthy Aging in Neighborhoods of Diversity across the Life Span (HANDLS) study
}

\author{
May A Beydoun ${ }^{1, *}$, Marie T Fanelli Kuczmarski ${ }^{2}$, Youfa Wang ${ }^{3}$, Marc A Mason ${ }^{4}$, \\ Michele K Evans ${ }^{1}{ }^{\dagger}$, and Alan B Zonderman ${ }^{1} \uparrow$ \\ 'National Institute on Aging, NIA/NIH-IRP, NIH Biomedical Research Center, 251 Bayview Blvd, Suite \\ 100-Room \#04B 1 18, Baltimore, MD 21224, USA: ${ }^{2}$ Department of Health, Nutrition and Exercise Sciences, \\ University of Delaware, Newark, DE, USA: ${ }^{3}$ Center for Human Nutrition, Department of International Health, \\ Johns Hopkins University, Baltimore, MD, USA: ${ }^{4}$ Statistical Information Systems, MedStar Research Institute, \\ Baltimore, MD, USA
}

Submitted 31 March 2010: Accepted 7 August 2010: First published online 21 September 2010

\begin{abstract}
Objective: To assess the predictive values of various adiposity indices for metabolic syndrome (MetS) among adults using baseline data from the Healthy Aging in Neighborhoods of Diversity across the Life Span (HANDLS) cohort.

Design: In a cross-sectional study, BMI, waist circumference (WC), body composition by dual-energy X-ray absorptiometry (DEXA) and metabolic risk factors such as TAG, HDL cholesterol, blood pressure, fasting glucose and insulin, uric acid and C-reactive protein were measured. Receiver-operating characteristic (ROC) curves and logistic regression analyses were conducted.

Setting: Baltimore, Maryland.

Subjects: White and African-American US adults ( $n$ 1981), aged 30-64 years.

Results: In predicting risk of MetS using obesity-independent National Cholesterol Education Program Adult Treatment Panel III criteria, percentage total body fat mass (TtFM) assessed using DEXA measuring overall adiposity had no added value over WC. This was true among both men (area under the ROC curve (AUC) $=0.680 v$. 0.733 for TtFM and WC, respectively; $P<0.05$ ) and women (AUC $=0.581 v .0 \cdot 686$ ). Percentage rib fat mass (RbFM) was superior to TtFM only in women for MetS (AUC $=0.701$ and 0.581 for RbFM and TtFM, respectively; $P<0.05$ ), particularly among African-American women. Elevated percentage leg fat mass (LgFM) was protective against MetS among African-American men. Among white men, BMI was inferior to WC in predicting MetS. Optimal WC cut-off points varied across ethnic-sex groups and differed from those recommended by the National Institutes of Health/ North American Association for the Study of Obesity.

Conclusions: The study provides evidence that WC is among the most powerful tools to predict MetS, and that optimal cut-off points for various indices including WC may differ by sex and race.
\end{abstract}

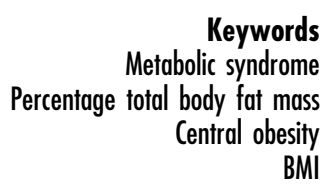

Various measures of obesity, particularly BMI and waist circumference (WC), have been used independently or combined with other criteria to define the metabolic syndrome (MetS). In 2001, WC was included in the MetS definition by the National Cholesterol Education Program (NCEP) Adult Treatment Panel III (ATP III) ${ }^{(1)}$. Hence, the wide use of WC makes it currently the reference measurement in defining the central obesity component of MetS. MetS is a clustering of several cardiometabolic risk factors which are linked to increased all-cause and

+ Co-senior authors. cardiovascular mortality ${ }^{(2-5)}$. Recently, studies suggested that while BMI and WC are both easily measurable indices of obesity, percentage total body fat may better predict MetS and future health risk. Percentage total body fat has frequently been used as the gold standard in receiveroperating characteristic (ROC) curve analyses examining the predictive value of various anthropometric measurements among children or adolescents ${ }^{(6-9)}$ and among adults $^{(10,11)}$. Thus, we need larger databases with total body fat ${ }^{(12)}$.

It is still debatable whether percentage total body fat mass (TtFM) is more valuable than the widely used 
anthropometric measures, particularly $\mathrm{WC}^{(13-27)}$, and virtually unknown whether percentage regional body fat among US adults has a higher value in predicting MetS and its components than WC or TtFM. Moreover, no previous studies have investigated appropriate cut-off points for those regional body fat indices that would have the highest predictive value of MetS and which cut-off point of WC best defines central obesity for each sociodemographic category such as sex-race groups ${ }^{(1,28-30)}$.

The present study is one of few in a growing literature ${ }^{(17,19,21,22,26)}$ to examine the predictive value of dualenergy X-ray absorptiometry (DEXA) body fat indices as opposed to anthropometric indices for MetS and its components using baseline data collected in a large cohort study. A number of other recent studies have measured percentage body fat (total and regional) with other methods such as bioelectrical impedence and computed tomography and compared their predictive value to anthropometric measures against MetS components ${ }^{(14-16,18,23-25,27)}$. In the present study, we systematically compared the values of $\mathrm{BMI}$ and various regional body fat indices to $\mathrm{WC}$ and TtFM in predicting MetS and its components across sexes and sex-ethnic groups. Second, we estimated related cut-off points with optimal sensitivity and specificity for MetS, and assessed the association between various adiposity measures and MetS by estimating adjusted odds ratios.

\section{Materials and methods}

\section{Setting and participants}

The Healthy Aging in Neighborhoods of Diversity Across the Life Span (HANDLS) is a prospective longitudinal study of a baseline representative sample of African-Americans and whites between 30 and 64 years of age. Participants were recruited as a fixed cohort by household screenings from an area probability sample of twelve census segments in Baltimore City. Data were collected in two separate phases. Phase 1 consisted of screening, recruitment, a household interview (assessing sociodemographic information and physiological and psychological chronic exposure) and a first $24 \mathrm{~h}$ recall; phase 2 consisted of an in-depth examination in a mobile medical research vehicle (MRV) and included a second dietary assessment with a $24 \mathrm{~h}$ recall, psychometric measures (e.g. for depressive symptoms and cognitive function), anthropometric and body composition measurements.

Out of the targeted 4000 adults, 3724 were selected in the household survey at phase 1 from 2004 to 2008 (sample 1). Thus far, $2436(65.4 \%)$ had complete baseline phase 2 examinations by 2008 (sample 2). However, only about $53.2 \%$ (sample $3 \mathrm{~A} ; n$ 1981) of those had complete DEXA scans. Moreover, complete metabolic outcome data were found among $88 \%$ to $98 \%$ of sample 3, depending on the metabolic parameter being measured. Sample 3B with complete data on DEXA scans and MetS (definition 1) components ( $n$ 1819) differed from the remainder of sample 1 , by being older (mean age $48 \cdot 2$ (SD 9.1) $v .47 \cdot 2$ (SD 9.5) years, respectively; $P<0.05$ based on $t$ test), having a significantly higher proportion of women $(57 \cdot 0 \% v$. $52.6 \% ; P<0.05$ based on $\chi^{2}$ test) and a larger proportion with poverty:income ratio (PIR) $<125 \%(47 \cdot 0 \%$ v. $35 \cdot 8 \%$; $P<0.05$ based on $\chi^{2}$ test).

\section{Body composition analysis}

DEXA was performed using a Lunar DPX-IQ analyser (Lunar Corp., Madison, WI, USA). The total body scan measures both body composition and bone mineral density and yields results for the total body as well as specific regions. Several measures were of interest, including TtFM (total body fat mass as a percentage of total body mass) and body fat mass in specific regions, i.e. arms (AmFM), legs (LgFM), trunk (TrFM), ribs (RbFM), pelvis (PIFM) and spine (SpFM), as a percentage of total fat mass (TFM).

\section{Antbropometric indices}

Body weight and standing height were measured directly on a calibrated scale with a calibrated ruler set parallel to the top of the participant's head. BMI (=weight $/$ height ${ }^{2}, \mathrm{~kg} / \mathrm{m}^{2}$ ) was calculated for each subject. WC (in $\mathrm{cm}$ ) was measured using a tape measure starting from the hip bone and wrapping around the waist at the level of the navel.

\section{Metabolic outcome variables}

Systolic and diastolic blood pressure

The average of right and left sitting blood pressure values was taken to represent each of systolic and diastolic blood pressure levels (SBP and DBP, respectively) for the present analyses. Blood pressure was measured non-invasively using the brachial artery auscultation method with an aneroid manometer, a stethoscope and an inflatable cuff.

\section{Other metabolic risk factors}

Following an overnight fast (generally at least $8 \mathrm{~h}$, but for most $12 \mathrm{~h}$ ), blood samples were drawn from an antecubital vein. Blood was collected first thing after consenting, after which breakfast was served. Total cholesterol (TC), HDL-cholesterol (HDL-C), TAG, uric acid and glucose were assessed using a spectrophotometer (AU5400 Immuno Chemistry Analyser; Olympus, Center Valley, PA, USA). Fasting serum insulin was analysed with a standard immunoassay test (Immulite ${ }^{\circledR} 2000$ Immunoassay System; Siemens/DPC, Eschborn, Germany) and C-reactive protein (CRP) was analysed with an immunoturbidimeter (Nephelometer II; Siemens/Behring, Minsk, Republic of Belarus). Homeostasis model assessmentinsulin resistance (HOMA-IR) ${ }^{(31)}$ was computed, with a cut-off point of $2 \cdot 61$ reflecting high insulin resistance level as suggested elsewhere ${ }^{(32)}$. Cut-offs for hyperuricaemia were $>7 \mathrm{mg} / \mathrm{dl}$ in men and $>6 \mathrm{mg} / \mathrm{dl}$ in women ${ }^{(33)}$, while elevated CRP was defined as $>2 \cdot 11 \mathrm{mg} / \mathrm{l}^{(34)}$. 


\section{Metabolic syndrome}

Central obesity was defined as $\mathrm{WC} \geq 102 \mathrm{~cm}$ (40 in.) for men or $\mathrm{WC} \geq 88 \mathrm{~cm}$ (35 in.) for women ${ }^{(35)}$. This is one of five components of the NCEP ATP III (2001) main definition of MetS (definition 1). Using this definition, MetS was positive when three or more of the following criteria screened as positive: (i) $\mathrm{WC} \geq 102 \mathrm{~cm}$ for men or $\mathrm{WC} \geq 88$ $\mathrm{cm}$ for women; (ii) SBP/DBP $\geq 130 / 85 \mathrm{mmHg}$; (iii) fasting glucose $\geq 110 \mathrm{mg} / \mathrm{dl}$; (iv) $\mathrm{TAG} \geq 150 \mathrm{mg} / \mathrm{dl}$; (v) HDL$\mathrm{C}<40 \mathrm{mg} / \mathrm{dl}$ for men or HDL-C $<50 \mathrm{mg} / \mathrm{dl}$ for women.

A second MetS definition (definition 2; the main one in our analysis) used criteria (ii), (iii) and (iv) of the first definition with a cut-off point of two or more instead of three or more positive components. This was done to produce a measure of MetS that is independent of adiposity. This definition was used for the target outcome in the ROC curve analysis, as was done by at least one previous study ${ }^{(24)}$.

\section{Covariates}

Other covariates were considered mainly as potential confounders or effect modifiers. These included age group, sex, race (white $v$. African-American), marital status (married $v$. unmarried), smoking status (ever $v$. never smoker) and self-reported use of medications for diabetes, hyperlipidaemia and hypertension diagnosis, based on the coding of the 9th edition of the International Statistical Classification of Diseases and Related Health Problems (ICD-9) ${ }^{(36)}$. Socio-economic status was measured by completed years of education (categorized as: $<$ high school, 0-8 years; high school, (9-12 years); $>$ high school, 13+ years) and PIR (categorized as: below poverty, PIR $<125 \%$; above poverty, PIR $\geq 125 \%$ ).

\section{Statistical analysis}

The STATA statistical software package release 10.0 (Stata Corporation, College Station, TX, USA) was used to analyse data. All analyses were stratified by sex, and some by sex and race. We used the two-sided independent-samples $t$ test to compare means across dichotomous variables (i.e. men $v$. women, white men $v$. African-American men, white women $v$. African-American women); the one-way ANOVA test for comparison of means across multilevel variables followed by post hoc analysis adjusted for multiple comparisons using the Bonferroni technique; and Peason's $\chi^{2}$ test to examine differences in proportions across categorical variables.

Sensitivity (proportion of true positives, i.e. proportion of cases correctly identified as meeting the conditions of MetS) and specificity (proportion of true negatives, i.e. proportion of non-cases correctly identified as not meeting MetS) were calculated to evaluate the accuracy of body fat and anthropometric indices in depicting MetS (definition 2), by creating ROC curves ${ }^{(37,38)}$. The ROC curve is a graphical plot of sensitivity $v$. ( $1-$ specificity) for a binary classifier system as its discrimination threshold is varied. The area beneath each ROC curve (AUC), a measure that is independent of classifier cut-off points, can range between 0 and 1 and be computed with its 95\% confidence interval.

An index positively associated with MetS would yield an AUC between 0.5 and 1.0 . An AUC value of 0.7 , for instance, has the following interpretation. If we randomly select from the MetS ${ }^{+}$and MetS ${ }^{-}$groups, the value of that particular adiposity index will be greater in the $\mathrm{MetS}^{+}$ group $70 \%$ of the time. Raw continuous values for each adiposity index were used for that purpose. When two or more empirical curves are constructed based on tests performed on the same individuals, statistical analysis on differences between curves must take into account the correlated nature of the data. To this end, a non-parametric approach to the analysis of areas under correlated ROC curves was performed, by using the theory on generalized $U$-statistics to generate an estimated covariance matrix ${ }^{(39)}$. Additionally, $P$ values were adjusted for multiple comparisons using the Bonferroni technique ${ }^{(39)}$. The two reference measurements considered were WC (as it is incorporated in the original NCEP ATP III definition of MetS) ${ }^{(1)}$ and TtFM (as it was suggested by various studies to be superior to other measures) ${ }^{(12)}$. To ensure that all other test measures (e.g. BMI, DEXA measures) were positively associated with WC and TtFM, correlation coefficients were estimated (see Appendix 1). Measures that correlated negatively with either WC or TtFM were entered into the ROC curve analysis as their negative value.

Optimal cut-off points for each adiposity index were derived from MetS (definition 2) ROC curve analysis using the highest sensitivity and specificity combination, corresponding to the smallest distance from the upper left-hand corner to the diagonal (see Fig. 1). Finally, using multivariate logistic regression analyses, binary adiposity indices (based on optimal cut-off points) as well as standardized $Z$-scores were modelled against MetS (definition 2). Following this analysis, a sensitivity analysis was conducted to examine the added value of DEXA measures over anthropometric measures, by combining multivariate logistic regression models with ROC curves. Changes in AUC between successive models of more than $10 \%$ of the preceding model indicated appreciable added value. To this end, a series of three multiple logistic regression models was conducted per sex group to predict MetS (definition 2) with the following predictors: model 1, BMI plus WC; model 2, as model 1 plus all DEXA adiposity measures considered in previous analyses with a sex-specific cut-off point; model 3, as model 2 plus covariates. A type I error of 0.05 was considered in all analyses.

\section{Results}

\section{Characteristics of the study population}

Study population characteristics are shown in Table 1. Men overall were more likely to be married compared 
Table 1 Study population characteristics (mean and standard deviation or percentage), by sex and by sex-race, among participants with complete data on DEXA scan measures and MetS (definition 1) components: HANDLS study

\begin{tabular}{|c|c|c|c|c|c|c|c|c|c|c|c|c|c|c|c|c|c|}
\hline & \multicolumn{2}{|c|}{$\begin{array}{l}\text { Total } \\
(n 1819)\end{array}$} & \multicolumn{2}{|c|}{$\begin{array}{l}\text { Men } \\
(n 783)\end{array}$} & \multicolumn{2}{|c|}{$\begin{array}{l}\text { Women } \\
(n \text { 1036) }\end{array}$} & & \multicolumn{2}{|c|}{$\begin{array}{l}\text { White men } \\
\quad(n \text { 314) }\end{array}$} & \multicolumn{2}{|c|}{$\begin{array}{l}\text { African-American men } \\
(n \text { 425) }\end{array}$} & & \multicolumn{2}{|c|}{$\begin{array}{l}\text { White women } \\
\text { (n 469) }\end{array}$} & \multicolumn{2}{|c|}{$\begin{array}{l}\text { African-American women } \\
(n \text { 611) }\end{array}$} & \\
\hline & Mean or \% & SD & Mean or \% & SD & Mean or \% & SD & & Mean or \% & SD & Mean or \% & SD & & Mean or \% & SD & Mean or \% & SD & \\
\hline \multicolumn{18}{|l|}{ DEMOGRAPHICS } \\
\hline Age (years) & $48 \cdot 3$ & $9 \cdot 1$ & $48 \cdot 2$ & $9 \cdot 2$ & $48 \cdot 3$ & $9 \cdot 1$ & & $48 \cdot 5$ & $9 \cdot 3$ & $47 \cdot 9$ & $9 \cdot 0$ & & $48 \cdot 2$ & $9 \cdot 4$ & $48 \cdot 4$ & 8.9 & \\
\hline $\mathrm{PIR}<125 \%(\%)$ & $47 \cdot 0$ & & $44 \cdot 2$ & & $49 \cdot 0$ & & a & $30 \cdot 9$ & & $53 \cdot 1$ & & a & $40 \cdot 0$ & & $55 \cdot 3$ & & a \\
\hline \multicolumn{18}{|l|}{ Educational attainment (\%) } \\
\hline$<$ High school & $7 \cdot 0$ & & $8 \cdot 4$ & & $6 \cdot 0$ & & a & $12 \cdot 9$ & & $5 \cdot 6$ & & $\mathrm{a}$ & $8 \cdot 0$ & & $4 \cdot 8$ & & $\mathrm{a}$ \\
\hline High school & $59 \cdot 0$ & & $60 \cdot 7$ & & $57 \cdot 5$ & & & $48 \cdot 0$ & & $68 \cdot 4$ & & & 53.5 & & $60 \cdot 0$ & & \\
\hline$>$ High school & $34 \cdot 1$ & & $30 \cdot 9$ & & $36 \cdot 5$ & & & $39 \cdot 1$ & & $26 \cdot 0$ & & & 38.5 & & $35 \cdot 2$ & & \\
\hline Married (\%) & $55 \cdot 3$ & & $63 \cdot 3$ & & $49 \cdot 2$ & & a & $68 \cdot 4$ & & $60 \cdot 0$ & & a & $58 \cdot 1$ & & $42 \cdot 6$ & & $\mathrm{a}$ \\
\hline \multicolumn{18}{|l|}{ ANTHROPOMETRIC INDICES } \\
\hline BMI $\left(\mathrm{kg} / \mathrm{m}^{2}\right)$ & $29 \cdot 2$ & $7 \cdot 3$ & $27 \cdot 3$ & $5 \cdot 3$ & $30 \cdot 6$ & $8 \cdot 2$ & a & $28 \cdot 3$ & $5 \cdot 3$ & $26 \cdot 6$ & $5 \cdot 1$ & a & $29 \cdot 6$ & $7 \cdot 6$ & $31 \cdot 3$ & $8 \cdot 6$ & a \\
\hline WC $(\mathrm{cm})$ & $97 \cdot 0$ & $17 \cdot 8$ & $95 \cdot 7$ & $16 \cdot 5$ & $98 \cdot 0$ & $18 \cdot 8$ & a & $99 \cdot 9$ & $18 \cdot 1$ & $92 \cdot 9$ & $14 \cdot 7$ & a & $97 \cdot 4$ & $18 \cdot 2$ & $98 \cdot 3$ & $19 \cdot 2$ & \\
\hline \multicolumn{18}{|l|}{ BODY FAT INDICES } \\
\hline TtFM (of TBM) & $35 \cdot 1$ & $12 \cdot 2$ & $25 \cdot 2$ & 8.5 & $42 \cdot 6$ & $8 \cdot 7$ & a & $27 \cdot 7$ & $7 \cdot 5$ & $23 \cdot 5$ & $8 \cdot 7$ & $\mathrm{a}$ & $42 \cdot 1$ & $8 \cdot 5$ & $43 \cdot 0$ & $8 \cdot 8$ & \\
\hline AmFM (of TFM) & $7 \cdot 3$ & 1.9 & $6 \cdot 8$ & 1.5 & $7 \cdot 7$ & $2 \cdot 1$ & $\mathrm{a}$ & $6 \cdot 5$ & $1 \cdot 4$ & $7 \cdot 0$ & 1.5 & $\mathrm{a}$ & $7 \cdot 2$ & $2 \cdot 0$ & $8 \cdot 0$ & $2 \cdot 1$ & $\mathrm{a}$ \\
\hline LgFM (of TFM) & $36 \cdot 1$ & $5 \cdot 4$ & $34 \cdot 4$ & 4.9 & $37 \cdot 5$ & $5 \cdot 3$ & a & $32 \cdot 7$ & $5 \cdot 0$ & $35 \cdot 5$ & 4.5 & $\mathrm{a}$ & $37 \cdot 1$ & $5 \cdot 6$ & $37 \cdot 7$ & $5 \cdot 2$ & $\mathrm{a}$ \\
\hline TrFM (of TFM) & $50 \cdot 6$ & $6 \cdot 0$ & $52 \cdot 9$ & $5 \cdot 6$ & 48.9 & $5 \cdot 7$ & a & $55 \cdot 1$ & $5 \cdot 4$ & 51.5 & $5 \cdot 2$ & $\mathrm{a}$ & $49 \cdot 9$ & $5 \cdot 8$ & $48 \cdot 2$ & $5 \cdot 5$ & a \\
\hline RbFM (of TFM) & $19 \cdot 2$ & $3 \cdot 7$ & $20 \cdot 0$ & $3 \cdot 8$ & $18 \cdot 6$ & $3 \cdot 6$ & a & $21 \cdot 4$ & $3 \cdot 6$ & $19 \cdot 1$ & $3 \cdot 6$ & $\mathrm{a}$ & $18 \cdot 8$ & $3 \cdot 7$ & $18 \cdot 5$ & $3 \cdot 4$ & \\
\hline PIFM (of TFM) & $17 \cdot 5$ & $2 \cdot 8$ & $17 \cdot 9$ & $2 \cdot 8$ & $17 \cdot 1$ & $2 \cdot 7$ & a & $18 \cdot 7$ & $2 \cdot 6$ & $17 \cdot 5$ & $2 \cdot 8$ & a & $17 \cdot 7$ & $2 \cdot 6$ & $16 \cdot 8$ & $2 \cdot 7$ & $\mathrm{a}$ \\
\hline SpFM (of TFM) & $12 \cdot 3$ & $2 \cdot 7$ & $13 \cdot 6$ & $2 \cdot 7$ & $11 \cdot 4$ & $2 \cdot 3$ & a & $13 \cdot 6$ & $2 \cdot 5$ & $13 \cdot 5$ & $2 \cdot 8$ & & 11.9 & $2 \cdot 2$ & $11 \cdot 2$ & $2 \cdot 3$ & $\mathrm{a}$ \\
\hline \multicolumn{18}{|l|}{ METABOLIC OUTCOMES } \\
\hline Fasting glucose $(\mathrm{mg} / \mathrm{dl})$ & $105 \cdot 1$ & $45 \cdot 0$ & $106 \cdot 2$ & $46 \cdot 0$ & $104 \cdot 2$ & $44 \cdot 1$ & $\mathrm{a}$ & $109 \cdot 6$ & $45 \cdot 9$ & $104 \cdot 0$ & $46 \cdot 0$ & & $103 \cdot 4$ & $41 \cdot 4$ & $104 \cdot 7$ & $46 \cdot 0$ & \\
\hline Fasting insulin (mU/l) & $11 \cdot 1$ & $10 \cdot 8$ & $10 \cdot 8$ & $10 \cdot 9$ & $11 \cdot 4$ & $10 \cdot 7$ & & $11 \cdot 9$ & $12 \cdot 1$ & $10 \cdot 0$ & $10 \cdot 0$ & a & $10 \cdot 8$ & $10 \cdot 2$ & $11 \cdot 8$ & $11 \cdot 0$ & \\
\hline HOMA-IRt $(\mathrm{mU} / \mathrm{l} \times \mathrm{mmol} / \mathrm{l})$ & $3 \cdot 1$ & $4 \cdot 1$ & $3 \cdot 1$ & $4 \cdot 5$ & $3 \cdot 2$ & $3 \cdot 8$ & & 3.5 & $4 \cdot \cdot 2$ & 2.9 & $4 \cdot 6$ & & $3 \cdot 0$ & $3 \cdot 7$ & $3 \cdot 3$ & 3.9 & \\
\hline TAG $(\mathrm{mg} / \mathrm{dl})$ & $125 \cdot 1$ & $100 \cdot 1$ & $135 \cdot 1$ & $121 \cdot 4$ & $117 \cdot 5$ & $79 \cdot 6$ & a & $169 \cdot 7$ & $149 \cdot 2$ & 111.9 & $91 \cdot 7$ & a & $138 \cdot 1$ & $101 \cdot 8$ & $103 \cdot 2$ & $55 \cdot 1$ & a \\
\hline $\mathrm{TC}(\mathrm{mg} / \mathrm{dl})$ & $188 \cdot 3$ & $43 \cdot 8$ & $184 \cdot 6$ & $46 \cdot 2$ & $191 \cdot 1$ & $41 \cdot 7$ & a & $188 \cdot 3$ & $45 \cdot 2$ & $182 \cdot 1$ & $46 \cdot 7$ & & $195 \cdot 7$ & $42 \cdot 4$ & $188 \cdot 0$ & $40 \cdot 9$ & a \\
\hline HDL-C (mg/dl) & $53 \cdot 1$ & $17 \cdot 4$ & $49 \cdot 3$ & $17 \cdot 6$ & $56 \cdot 0$ & $16 \cdot 8$ & a & $43 \cdot 6$ & $12 \cdot 0$ & $53 \cdot 2$ & $19 \cdot 5$ & $\mathrm{a}$ & $53 \cdot 5$ & $15 \cdot 1$ & $57 \cdot 7$ & $17 \cdot 8$ & a \\
\hline Uric acid (mg/dl) & $5 \cdot 3$ & $1 \cdot 6$ & $5 \cdot 9$ & 1.5 & 4.9 & 1.5 & a & $5 \cdot 9$ & $1 \cdot 4$ & $6 \cdot \overline{0}$ & 1.5 & & $4 \cdot 7$ & $1 \cdot 4$ & $5 \cdot 0$ & 1.5 & a \\
\hline $\operatorname{CRP}(\mathrm{mg} / \mathrm{l})$ & $4 \cdot 1$ & $5 \cdot 9$ & $3 \cdot 1$ & $4 \cdot 8$ & 4.9 & $6 \cdot 5$ & a & $2 \cdot 9$ & 3.3 & $3 \cdot 3$ & $5 \cdot 6$ & & $4 \cdot 4$ & $5 \cdot 3$ & $5 \cdot 3$ & $7 \cdot 1$ & a \\
\hline SBP $(\mathrm{mmHg})$ & $119 \cdot 1$ & $19 \cdot 4$ & $119 \cdot 7$ & $17 \cdot 4$ & $118 \cdot 6$ & $20 \cdot 8$ & & $119 \cdot 2$ & $17 \cdot 3$ & $120 \cdot 2$ & $17 \cdot 5$ & & $115 \cdot 0$ & $18 \cdot 7$ & $121 \cdot 1$ & $21 \cdot 8$ & a \\
\hline $\mathrm{DBP}(\mathrm{mmHg})$ & $72 \cdot 3$ & $12 \cdot 2$ & $73 \cdot 8$ & $11 \cdot 6$ & $71 \cdot 1$ & $12 \cdot 4$ & a & $74 \cdot 0$ & 11.5 & $73 \cdot 7$ & $11 \cdot 7$ & & $70 \cdot 2$ & $11 \cdot 5$ & $71 \cdot 8$ & $13 \cdot 0$ & a \\
\hline \multicolumn{18}{|l|}{ METABOLIC SYNDROME } \\
\hline MetS (definition 1)‡ (\%) & $\begin{array}{c}25 \cdot 3 \\
(n 460)\end{array}$ & & $\begin{array}{r}22 \cdot 0 \\
(n 172)\end{array}$ & & $\begin{array}{c}27 \cdot 8 \\
(n 288)\end{array}$ & & $\mathrm{a}$ & $\begin{array}{r}31.8 \\
(n 100)\end{array}$ & & $\begin{array}{r}15 \cdot 3 \\
(n 129)\end{array}$ & & $\mathrm{a}$ & $\begin{array}{r}30 \cdot 3 \\
(n 72)\end{array}$ & & $\begin{array}{r}26 \cdot 0 \\
(n 159)\end{array}$ & & \\
\hline MetS (definition 2)‡ (\%) & $\begin{array}{r}17.5 \\
(n 319)\end{array}$ & & $\begin{array}{c}20 \cdot 0 \\
(n-157)\end{array}$ & & $\begin{array}{r}15 \cdot 6 \\
(n 162)\end{array}$ & & a & $\begin{array}{c}24.5 \\
(n 77)\end{array}$ & & $\begin{array}{r}17 \cdot 1 \\
(n 67)\end{array}$ & & a & $\begin{array}{r}15.8 \\
(n 80)\end{array}$ & & $\begin{array}{r}15.6 \\
(n 95)\end{array}$ & & \\
\hline
\end{tabular}

DEXA, dual-energy X-ray absorptiometry; MetS, metabolic syndrome; HANDLS, Healthy Aging in Neighborhoods of Diversity Across the Life Span; PIR, poverty:income ratio; WC, waist circumference; TtFM; percentage total body fat mass; TBM, total body mass; AmFM, percentage arm fat mass; TFM, total fat mass; LgFM, percentage leg fat mass; TrFM, percentage trunk fat mass; RbFM, percentage rib fat mass; PIFM, percentage pelvic fat mass; SpFM, percentage spine fat mass; HOMA-IR, homeostasis model assessment-insulin resistance; TC, total cholesterol; HDL-C, HDL cholesterol; CRP, C-reactive protein; SBP, systolic blood pressure; DBP, diastolic blood pressure.

${ }^{\mathrm{a}} P<0.05$ for the null hypothesis that means or proportions are equal between sexes or between race groups within each sex $\left(t\right.$ test or $\chi^{2}$ test)

${ }^{\mathrm{b}} P<0.05$ for the null hypothesis that means or proportions are equal between sex-race groups, i.e. white men and African-American men, white women and African-American women (ANOVA test or $\chi^{2}$ test) +HOMA-IR is the product of the fasting values of glucose $\left(G_{0}\right.$; expressed as $\left.\mathrm{mg} / \mathrm{dl}\right)$ and insulin $\left(I_{0}\right.$, expressed as $\left.\mu \mathrm{U} / \mathrm{ml}\right)$, divided by a constant: $I_{0} \times G_{0} / 405$.

¥Using definition 1, MetS was positive when three or more of the following criteria screened as positive. These criteria are derived from the National Cholesterol Education Program (NCEP) Adult Treatment Panel III (2001) (). (i) Central obesity NCEP component: WC $\geq 102 \mathrm{~cm}$ for men and WC $\geq 88 \mathrm{~cm}$ for women; (ii) blood pressure NCEP component: $\mathrm{SBP} / \mathrm{DBP} \geq 130 / 85 \mathrm{mmHg}$; (iii) fasting glucose NCEP component: fasting glucose $\geq 110 \mathrm{mg} / \mathrm{dl}$; (iv) dyslipidaemia-TAG NCEP component: TAG $\geq 150 \mathrm{mg} / \mathrm{dl}$; (v) dyslipidaemia-HDL-C NCEP component: HDL-C $<40 \mathrm{mg} / \mathrm{dl}$ for men and HDL-C $<50 \mathrm{mg} / \mathrm{dl}$ for women. Using definition 2 , MetS was
positive when two or more of the preceding criteria screened positive excluding criteria (i) and (v). 
Table 2 Adiposity indices and metabolic risk factors (mean and standard deviation), by MetS (definition 1)† and by sex: HANDLS study

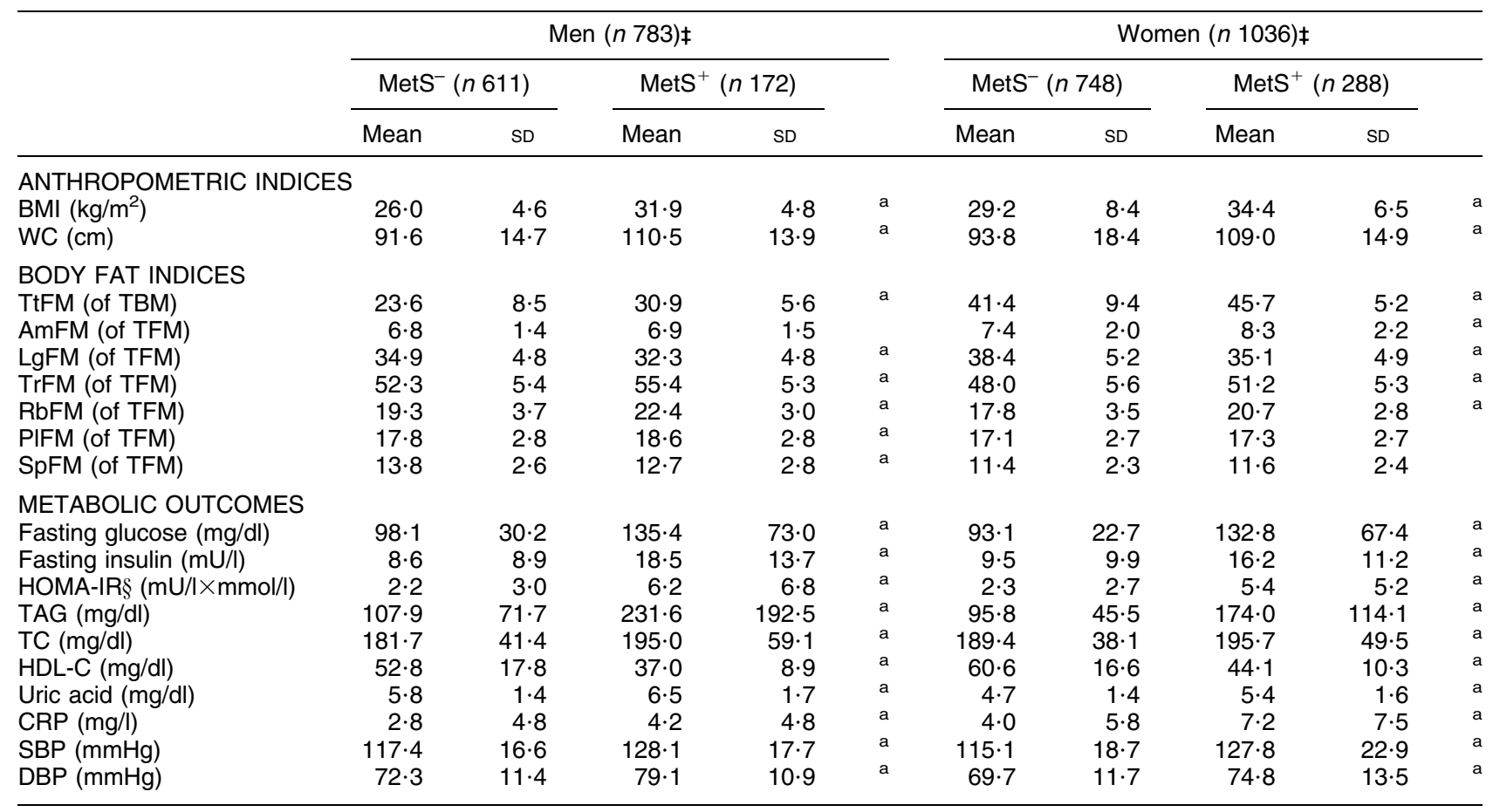

MetS, metabolic syndrome; HANDLS, Healthy Aging in Neighborhoods of Diversity Across the Life Span; WC, waist circumference; TtFM; percentage total body fat mass; TBM, total body mass; AmFM, percentage arm fat mass; TFM, total fat mass; LgFM, percentage leg fat mass; TrFM, percentage trunk fat mass; RbFM, percentage rib fat mass; PIFM, percentage pelvic fat mass; SpFM, percentage spine fat mass; HOMA-IR, homeostasis model assessment-insulin resistance; TC, total cholesterol; HDL-C, HDL cholesterol; CRP, C-reactive protein; SBP, systolic blood pressure; DBP, diastolic blood pressure.

${ }^{a} P<0.05$ for the null hypothesis that means or proportions are equal between MetS groups within each sex $(t$ test).

tSee Table 1, footnote $\neq$, for details on MetS (definition 1).

¥Sample sizes varied depending on metabolic outcomes.

SSee Table 1, footnote $t$, for details on HOMA-IR.

with women, and whites more than African-Americans within each sex. PIR $<125 \%$ proportions were significantly higher among women overall compared with men and higher among African-Americans compared with whites consistently for each sex. White men had the highest proportion in the $>$ high school category and there was a wider racial gap among men $(26 \cdot 0 \% v \cdot 39 \cdot 3 \%$ in African-American $v$. white men) than among women $(35.2 \% v .38 \cdot 5 \%$ in African-American $v$. white women). Mean BMI was highest among African-American women, while mean WC was highest among white men.

Mean TtFM was significantly higher among women compared with men. Among men, whites had higher mean TtFM compared with African-Americans, while no ethnic differences were detected among women. Percentage regional fat mass from TFM was higher among women in two of the selected regions (AmFM and LgFM), but was lower in the other regions. Means of AmFM and LgFM were higher among African-American men than their white counterparts, while the reverse was true for TrFM, RbFM and PlFM. Similarly, mean AmFM and LgFM were higher among African-American women compared with their white counterparts, while the reverse was true for TrFM, PIFM and SpFM (Table 1).

Men had worse metabolic profiles than women for fasting glucose, TAG, HDL-C, uric acid and DBP. Women had worse profiles for TC and CRP $(P<0 \cdot 05$ based on $t$ test between sex groups). Fasting insulin and lipid profiles (higher TAG and lower HDL-C) were worse among white men compared with African-American men. Among women, African-Americans had a worse profile than their white counterparts in terms of uric acid, CRP, SBP and DBP, whereas the reverse was true for TAG, TC and HDL-C $(P<0 \cdot 05$ based on $t$ test between ethnic groups and within each sex; Table 1).

MetS (definition 1) was significantly more prevalent among women than men $(27 \cdot 8 \% v \cdot 22 \cdot 0 \%)$, whereas the reverse was true for MetS (definition 2). Moreover, racial differences in MetS (definitions 1 and 2) prevalence proportions were significant only among men, with whites having the higher prevalence (Table 1).

Using definition 1, men and women with MetS had significantly higher adiposity in most regions except LgFM (where the reverse was true) and AmFM (where no significant association was detected). All other metabolic outcomes and anthropometric measures were significantly higher in the MetS ${ }^{+}$group compared with $\mathrm{MetS}^{-}$for both men and women (Table 2).

\section{Receiver-operating characteristic curve analysis}

Using WC as the reference measurement, BMI, TtFM, AmFM, PIFM and -SpFM were all inferior predictors for MetS (definition 2) in men, based on Bonferroni-corrected 
Table 3 ROC curve analysis (AUC and 95\% confidence interval) for MetS (definition 2)+ and metabolic risk factors predicted by adiposity indices: HANDLS study

\begin{tabular}{|c|c|c|c|c|c|c|}
\hline & \multicolumn{3}{|c|}{ Men $(n 783) \ddagger$} & \multicolumn{3}{|c|}{ Women $(n$ 1036) $\ddagger$} \\
\hline & AUC & $95 \% \mathrm{Cl}$ & & AUC & $95 \% \mathrm{Cl}$ & \\
\hline \multicolumn{7}{|l|}{ MetS (definition 2) $\dagger$} \\
\hline BMI $\left(\mathrm{kg} / \mathrm{m}^{2}\right)$ & 0.690 & $0.643,0.736$ & a & 0.656 & $0.616,0.701$ & $\mathrm{~b}$ \\
\hline WC (cm) & 0.733 & $0.690,0.775$ & $\mathrm{~b}$ & 0.686 & $0.643,0.727$ & $\mathrm{~b}$ \\
\hline TtFM (of TBM) & 0.680 & $0.637,0.723$ & a & 0.581 & $0.539,0.622$ & a \\
\hline AmFM (of TFM) & 0.513 & $0.462,0.564$ & $\mathrm{a}, \mathrm{b}$ & 0.580 & $0.535,0.625$ & \\
\hline -LgFM (of TFM) & 0.662 & $0.615,0.709$ & & 0.645 & $0.597,0.692$ & \\
\hline TrFM (of TFM) & 0.668 & $0.621,0.714$ & & 0.636 & $0.589,0.683$ & \\
\hline RbFM (of TFM) & 0.687 & $0.643,0.730$ & & $0 \cdot 701$ & $0.659,0.743$ & $\mathrm{~b}$ \\
\hline PIFM (of TFM) & 0.589 & $0.539,0.639$ & a & 0.502 & $0.453,0.551$ & a \\
\hline -SpFM (of TFM) $\S$ & 0.541 & $0.490,0.592$ & $a, b$ & 0.478 & $0.426,0.531$ & $a, b$ \\
\hline \multicolumn{7}{|c|}{ Blood pressure NCEP component† } \\
\hline $\mathrm{BMI}\left(\mathrm{kg} / \mathrm{m}^{2}\right)$ & 0.592 & $0.551,0.633$ & & 0.569 & $0.532,0.606$ & \\
\hline WC (cm) & 0.606 & $0.565,0.646$ & & 0.573 & $0.536,0.609$ & \\
\hline TtFM (of TBM) & 0.596 & $0.556,0.636$ & & 0.554 & $0.518,0.590$ & \\
\hline AmFM (of TFM) & 0.526 & $0.484,0.568$ & & 0.547 & $0.510,0.584$ & \\
\hline -LgFM (of TFM)§ & 0.607 & $0.566,0.648$ & & 0.557 & $0.520,0.594$ & \\
\hline TrFM (of TFM) & 0.598 & $0.557,0.639$ & & 0.547 & $0.509,0.585$ & \\
\hline RbFM (of TFM) & 0.575 & $0.535,0.616$ & & 0.569 & $0.532,0.605$ & \\
\hline PIFM (of TFM) & 0.543 & $0.501,0.584$ & & 0.487 & $0.449,0.525$ & a \\
\hline -SpFM (of TFM)§ & 0.483 & $0.441,0.525$ & $a, b$ & 0.469 & $0.431,0.507$ & $a, b$ \\
\hline \multicolumn{7}{|c|}{ Fasting glucose NCEP component $†$} \\
\hline BMI $\left(\mathrm{kg} / \mathrm{m}^{2}\right)$ & 0.697 & $0.650,0.743$ & & 0.714 & $0.676,0.752$ & $\mathrm{~b}$ \\
\hline WC $(\mathrm{cm})$ & 0.716 & $0.671,0.761$ & $\mathrm{~b}$ & 0.725 & $0.687,0.762$ & b \\
\hline TtFM (of TBM) & 0.673 & $0.627,0.718$ & a & 0.642 & $0.603,0.682$ & a \\
\hline AmFM (of TFM) & 0.544 & $0.493,0.595$ & $\mathrm{a}, \mathrm{b}$ & 0.633 & $0.590,0.675$ & a \\
\hline -LgFM (of TFM)§ & 0.590 & $0.536,0.643$ & a & 0.611 & $0.565,0.657$ & a \\
\hline TrFM (of TFM) & 0.594 & $0.541,0.646$ & a & 0.592 & $0.545,0.638$ & $\mathrm{a}$ \\
\hline RbFM (of TFM) & 0.650 & $0.603,0.697$ & a & 0.688 & $0.649,0.728$ & \\
\hline PIFM (of TFM) & 0.541 & $0.487,0.594$ & $a, b$ & 0.471 & $0.425,0.517$ & $a, b$ \\
\hline -SpFM (of TFM)§ & 0.581 & $0.530,0.632$ & $\mathrm{a}, \mathrm{b}$ & 0.498 & $0.448,0.549$ & $a, b$ \\
\hline \multicolumn{7}{|c|}{ Dyslipidaemia-TAG NCEP component† } \\
\hline BMI $\left(\mathrm{kg} / \mathrm{m}^{2}\right)$ & 0.653 & $0.610,0.695$ & a & 0.583 & $0.544,0.622$ & $a, b$ \\
\hline WC $(\mathrm{cm})$ & 0.690 & $0.649,0.731$ & & 0.632 & $0.593,0.671$ & $\mathrm{~b}$ \\
\hline TtFM (of TBM) & 0.666 & $0.625,0.706$ & & 0.533 & $0.494,0.572$ & $\mathrm{a}$ \\
\hline AmFM (of TFM) & 0.495 & $0.449,0.541$ & $a, b$ & 0.539 & $0.498,0.580$ & a \\
\hline -LgFM (of TFM)§ & 0.659 & $0.617,0.701$ & & 0.695 & $0.658,0.733$ & $\mathrm{~b}$ \\
\hline TrFM (of TFM) & 0.653 & $0.611,0.695$ & & 0.691 & $0.653,0.729$ & b \\
\hline RbFM (of TFM) & 0.685 & $0.644,0.725$ & & 0.690 & $0.652,0.728$ & $a, b$ \\
\hline PIFM (of TFM) & 0.572 & $0.528,0.616$ & $a, b$ & 0.579 & $0.536,0.621$ & \\
\hline -SpFM (of TFM)§ & 0.537 & $0.491,0.582$ & $a, b$ & 0.427 & $0.383,0.470$ & $a, b$ \\
\hline \multicolumn{7}{|c|}{ Dyslipidaemia-HDL-C NCEP component† } \\
\hline BMI $\left(\mathrm{kg} / \mathrm{m}^{2}\right)$ & 0.653 & $0.611,0.695$ & & 0.638 & $0.604,0.671$ & $\mathrm{~b}$ \\
\hline WC $(\mathrm{cm})$ & 0.666 & $0.624,0.707$ & & 0.659 & $0.625,0.693$ & $\mathrm{~b}$ \\
\hline TtFM (of TBM) & 0.657 & $0.616,0.698$ & & 0.566 & $0.531,0.600$ & $\mathrm{a}$ \\
\hline AmFM (of TFM) & 0.493 & $0.448,0.538$ & $a, b$ & 0.571 & $0.535,0.606$ & $\mathrm{a}$ \\
\hline -LgFM (of TFM)§ & 0.581 & $0.538,0.324$ & a & 0.614 & $0.580,0.648$ & \\
\hline TrFM (of TFM) & 0.592 & $0.549,0.635$ & a & 0.608 & $0.573,0.643$ & \\
\hline $\mathrm{RbFM}$ (of TFM) & 0.656 & $0.615,0.697$ & & 0.653 & $0.619,0.689$ & $\mathrm{~b}$ \\
\hline PIFM (of TFM) & 0.541 & $0.496,0.586$ & $a, b$ & 0.516 & $0.480,0.551$ & a \\
\hline -SpFM (of TFM)§ & 0.582 & $0.536,0.627$ & $a, b$ & 0.491 & $0.455,0.527$ & $a, b$ \\
\hline \multicolumn{7}{|l|}{ HOMA-IR $>2 \cdot 61 \|$} \\
\hline BMI $\left(\mathrm{kg} / \mathrm{m}^{2}\right)$ & 0.795 & $0 \cdot 762,0 \cdot 828$ & & 0.778 & $0 \cdot 750,0.807$ & $\mathrm{~b}$ \\
\hline WC $(\mathrm{cm})$ & $0 \cdot 815$ & $0 \cdot 782,0 \cdot 847$ & & 0.783 & $0 \cdot 754,0 \cdot 811$ & $\mathrm{~b}$ \\
\hline TtFM (of TBM) & 0.782 & $0 \cdot 748,0.816$ & & 0.685 & $0.653,0.717$ & \\
\hline AmFM (of TFM) & 0.574 & $0.533,0.616$ & $a, b$ & 0.680 & $0.647,0.713$ & $\mathrm{a}$ \\
\hline$-\mathrm{LgFM}$ (of TFM) & 0.583 & $0.541,0.625$ & $a, b$ & 0.652 & $0.618,0.686$ & a \\
\hline TrFM (of TFM) & 0.593 & $0.552,0.635$ & $a, b$ & 0.618 & $0.583,0.653$ & a \\
\hline RbFM (of TFM) & 0.703 & $0.666,0.739$ & $a, b$ & 0.731 & $0 \cdot 700,0.761$ & a \\
\hline PIFM (of TFM) & 0.517 & $0.474,0.560$ & $a, b$ & $0 \cdot 480$ & $0.443,0.516$ & $a, b$ \\
\hline -SpFM (of TFM)§ & 0.632 & $0.591,0.674$ & $a, b$ & 0.527 & $0.491,0.564$ & $a, b$ \\
\hline \multicolumn{7}{|c|}{ Uric acid $>6 \mathrm{mg} / \mathrm{dl}$ (women), $>7 \mathrm{mg} / \mathrm{dl}$ (men) } \\
\hline BMI $\left(\mathrm{kg} / \mathrm{m}^{2}\right)$ & 0.631 & $0.582,0.680$ & & 0.682 & $0.640,0.724$ & \\
\hline WC (cm) & 0.626 & $0.577,0.675$ & & 0.693 & $0.653,0.734$ & \\
\hline TtFM (of TBM) & 0.627 & $0.580,0.673$ & & 0.644 & $0.604,0.685$ & \\
\hline AmFM (of TFM) & 0.504 & $0.455,0.554$ & $a, b$ & 0.620 & $0.577,0.662$ & $\mathrm{a}$ \\
\hline$-\mathrm{LgFM}$ (of TFM)§ & 0.560 & $0.511,0.608$ & & 0.596 & $0.551,0.640$ & $\mathrm{a}$ \\
\hline TrFM (of TFM) & 0.561 & $0.513,0.610$ & & 0.578 & $0.534,0.623$ & a \\
\hline
\end{tabular}




\begin{tabular}{|c|c|c|c|c|c|c|}
\hline & \multicolumn{3}{|c|}{ Men $(n$ 783) $\ddagger$} & \multicolumn{3}{|c|}{ Women $(n$ 1036)‡ } \\
\hline & AUC & $95 \% \mathrm{Cl}$ & & AUC & $95 \% \mathrm{Cl}$ & \\
\hline RbFM (of TFM) & 0.603 & $0.555,0.651$ & & 0.655 & $0.614,0.696$ & \\
\hline PIFM (of TFM) & 0.513 & $0.463,0.564$ & $a, b$ & 0.509 & $0.464,0.555$ & $a, b$ \\
\hline -SpFM (of TFM)§ & 0.531 & $0.480,0.582$ & $a, b$ & 0.534 & $0.489,0.584$ & $a, b$ \\
\hline \multicolumn{7}{|l|}{$\mathrm{CRP}>2.11 \mathrm{mg} / \mathrm{l}$} \\
\hline BMI $\left(\mathrm{kg} / \mathrm{m}^{2}\right)$ & 0.636 & $0.595,0.677$ & & 0.732 & $0.701,0.764$ & \\
\hline WC $(\mathrm{cm})$ & 0.646 & $0.605,0.686$ & & 0.740 & $0.709,0.771$ & \\
\hline TtFM (of TBM) & 0.672 & $0.632,0.712$ & & 0.711 & $0.679,0.744$ & \\
\hline AmFM (of TFM) & 0.526 & $0.483,0.568$ & $a, b$ & 0.632 & $0.598,0.667$ & $a, b$ \\
\hline -LgFM (of TFM) & 0.518 & $0.476,0.561$ & $a, b$ & 0.626 & $0.591,0.661$ & $a, b$ \\
\hline TrFM (of TFM) & 0.526 & $0.483,0.568$ & $a, b$ & 0.615 & $0.580,0.650$ & $a, b$ \\
\hline RbFM (of TFM) & 0.567 & $0.525,0.609$ & $a, b$ & 0.659 & $0.624,0.693$ & a \\
\hline PIFM (of TFM) & 0.505 & $0.462,0.547$ & $a, b$ & 0.521 & $0.484,0.557$ & $a, b$ \\
\hline -SpFM (of TFM)s & 0.556 & 0.5140 .600 & $a, b$ & 0.496 & $0.460 \quad 0.532$ & $a, b$ \\
\hline
\end{tabular}

ROC, receiver-operating characteristic; AUC, area under the ROC curve; MetS, metabolic syndrome; HANDLS, Healthy Aging in Neighborhoods of Diversity Across the Life Span; WC, waist circumference; TtFM; percentage total body fat mass; TBM, total body mass; AmFM, percentage arm fat mass; TFM, total fat mass; LgFM, percentage leg fat mass; TrFM, percentage trunk fat mass; RbFM, percentage rib fat mass; PIFM, percentage pelvic fat mass; SpFM, percentage spine fat mass; NCEP, National Cholesterol Education Program; HDL-C, HDL cholesterol; HOMA-IR, homeostasis model assessment-insulin resistance; CRP, C-reactive protein.

${ }^{\text {a } P}<0.05$ for the null hypothesis that AUC for a specific test measure is the same as that of the reference measurement (WC, $\left.\mathrm{cm}\right)$; Bonferroni adjustment for multiple comparisons was used.

${ }^{\mathrm{b}} \mathrm{P}<0.05$ for the null hypothesis that AUC for a specific test measure is the same as that of the alternative reference measurement (TfFM); Bonferroni adjustment for multiple comparisons was used.

tSee Table 1, footnote $\ddagger$, for details on MetS (definition 2).

$\ddagger$ Sample sizes varied depending on metabolic outcomes.

$\S A \cup C$ values were obtained based on a ROC curve analysis in which LgFM and SpFM observed values were multiplied by -1 .

ISee Table 1, footnote $t$, for details on HOMA-IR.

$P$ values comparing AUC (Table 3). In women, BMI and WC had equal value in predicting MetS, while TtFM, PlFM and -SpFM were inferior to WC. Using TtFM as the reference measurement, WC was a superior predictor of MetS (definition 2) for both sexes, while BMI was a superior predictor for this outcome only among women. RbFM was equally valuable as WC and TtFM among men, and was more valuable than TtFM among women.

Stratifying by sex-race groups and considering only WC, BMI, TtFM, TrFM and RbFM as test predictors, there were several main findings. First, among African-American men, all measures were equally predictive of MetS (definition 2). Second, among white men and women as well as African-American women, TtFM had a poorer predictive value compared with WC. Third, BMI had a lower predictive value than WC among white men only. Finally, RbFM but not TrFM had a higher predictive value than TtFM among African-American women, although RbFM had a lower predictive value than WC among white men (Figs 1(a) to (d)). A more detailed analysis with MetS (definition 2) and the other metabolic outcomes by sex-race groups is presented in Appendix 2.

Examining each NCEP component of MetS (Table 3), adiposity was a weak predictor of hypertension (AUC $<$ 0.60) for most indicators. In contrast, elevated fasting glucose was best predicted by WC for both sexes, with significantly poorer predictive value observed for TtFM and most other regional fat indicators. Compared with TtFM (as reference measurement), BMI was a significantly better predictor among women, while AmFM was a poorer predictor among men. Moreover, for both sexes, PIFM and-SpFM were poorer predictors for this outcome. Examining dyslipidaemia-TAG as the target outcome, BMI, AmFM, -LgFM and -SpFM had inferior predictive values compared with WC for both sexes. However, among women, RbFM was shown to have superior predictive value to both WC and TtFM for this outcome, whereas TrFM and-LgFM were shown to be superior to TtFM only.

BMI, WC, TtFM and RbFM were the most highly and equally predictive of dyslipidaemia-HDL-C among men, while women's WC and RbFM were better than TtFM at predicting that NCEP component. As for HOMA-IR, BMI, WC and TtFM were equally predictive among men, whereas BMI and WC were superior to TtFM among women. For uric acid and CRP, all three measures (BMI, WC and TtFM) were equally predictive of this outcome among both sexes.

\section{Cut-off points and logistic regression analyses}

Optimal cut-off points based on ROC curve analyses were higher among women than men in the case of BMI, WC, TtFM, AmFM and LgFM (Table 4). Among men, optimal cut-off points were generally lower among AfricanAmericans, especially for BMI, WC and TtFM.

Elevated BMI (based on sex-specific optimal cut-off point) was associated with $2 \cdot 41$-fold higher prevalence odds of MetS (definition 2) among men and 1.86-fold higher prevalence odds among women, after controlling for sociodemographic factors, smoking status and use of medications. Among both sexes, an elevated WC (above 

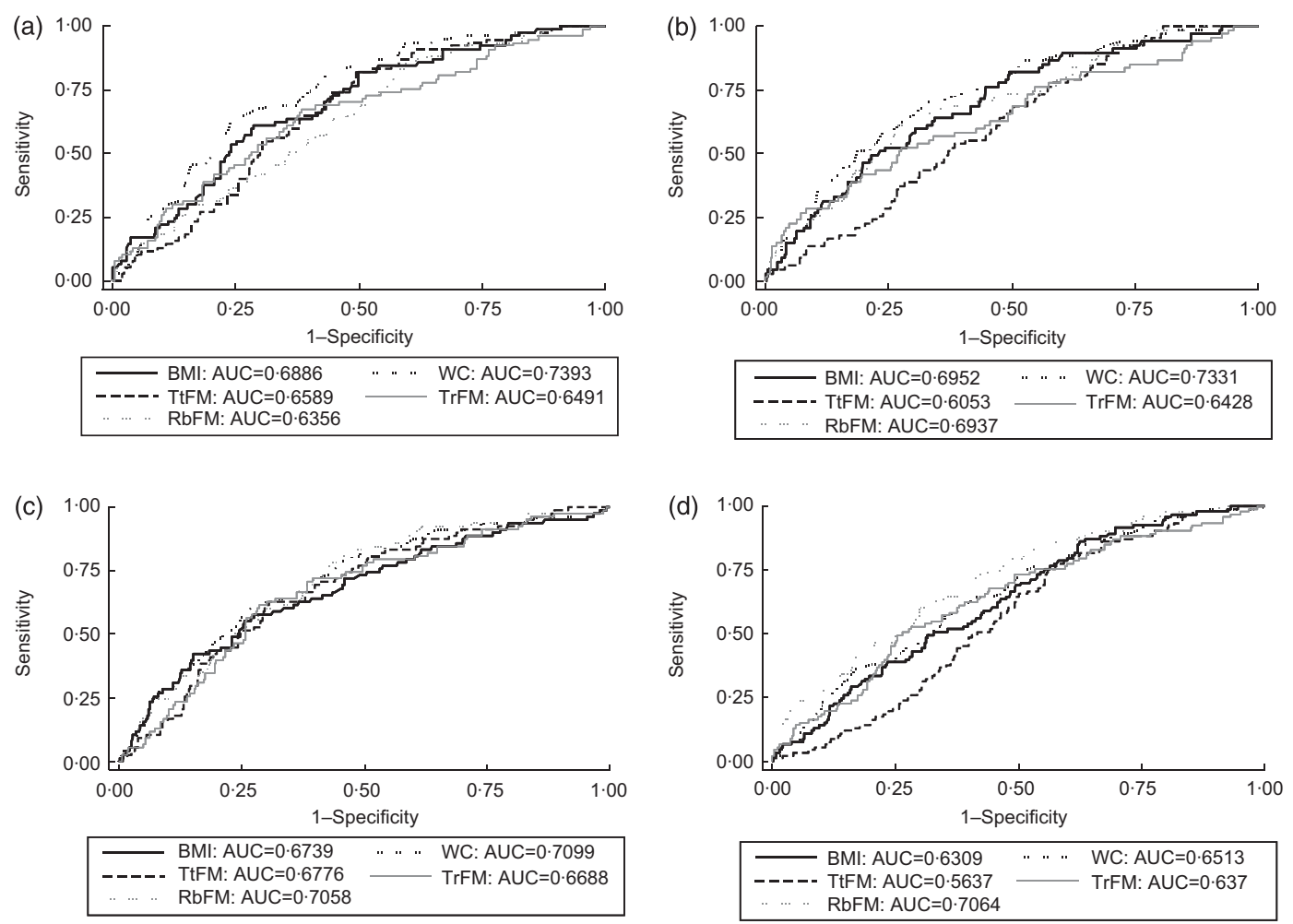

Fig. 1 Receiver-operating characteristic (ROC) curves and areas under the ROC curves (AUC) for selected adiposity indices (WC, waist circumference; TtFM, percentage total body fat mass; RbFM, percentage rib fat mass; TrFM, percentage trunk fat mass) for the prediction of metabolic syndrome (definition 2, see text) across ethnic-sex groups: Healthy Aging in Neighborhoods of Diversity Across the Life Span (HANDLS) study. (a) White men: AUC BMI, TtFM and RbFM were significantly lower than those for WC. Taking TtFM as the reference measurement, WC had a significantly higher AUC. (b) White women: AUC for TtFM compared with WC was significantly lower, based on Bonferroni-corrected $P$ value and taking WC as reference measurement. Both BMI and WC were superior to TtFM when taking the latter as reference measurement. (c) African-American men: all other AUC were not significantly different when taking WC and TtFM as reference measurement, respectively. (d) African-American women: AUC for TtFM compared with WC was significantly lower, based on Bonferroni-corrected $P$ value and taking WC as reference measurement. WC, BMI and RbFM had better predictive value than TtFM, when TtFM was the reference measurement

the sex-specific cut-off) was associated with $2 \cdot 37$ - to 2.95-fold higher prevalence odds of MetS (definition 2). Although the multivariate OR for elevated TtFM was $2 \cdot 34$ (95\% CI 1.56, 3.51) among men, this predictor was weaker among women with an OR of 1.39 (95\% CI 0.96, 2.02). For both sexes, elevated TrFM and RbFM significantly predicted MetS (definition 2). There were many findings regarding predictive value of adiposity measures for MetS (definition 2) when cut-offs were both sex- and race-specific. However, the most important one was that elevated LgFM was inversely associated with MetS (definition 2) only among African-American men ( $\mathrm{OR}=0 \cdot 39$; $95 \%$ CI $0 \cdot 22,0 \cdot 68)$. Considering standardized $Z$-scores of each adiposity measure in relation to MetS (definition 2), WC among white men had the highest predictive value with each 1 SD increasing the odds of MetS by $2 \cdot 82$-fold. Other adiposity measures that increased the odds of MetS (definition 2) by twofold or more included BMI and WC among all men, BMI and TtFM among white men, RbFM among all women, WC and RbFM among white women and RbFM among African-American women.

\section{Added predictive value of DEXA measures v. antbropometric measures}

Comparing a multivariate logistic regression model with only BMI+WC as predictors with a nested model that added DEXA measures to those anthropometric measures indicated that the AUC was increased by $11 \%$ (from 0.67 to 0.74 ) among men and $12 \%$ among women (from 0.63 to $0 \cdot 72$ ). Comparing the model with anthropometric and DEXA measures with a nested model in which covariates were added as predictors yielded a change in AUC by $8 \%$ (from 0.74 to $0 \cdot 80$ ) among men and $11 \%$ among women (from $0 \cdot 72$ to $0 \cdot 80$ ).

\section{Discussion}

Our study had a number of important findings. First, TtFM assessed using DEXA as a direct measure for overall adiposity had a lower value compared with anthropometric indices, particularly WC, in predicting MetS. This finding is consistent with previous studies that used a measure 
Table 4 Optimal cut-off points for MetS (definition 2)† prediction with adiposity indices, and multivariate-adjusted odds ratios with $95 \%$ confidence interval of MetS with binary adiposity indices: HANDLS study

\begin{tabular}{|c|c|c|c|c|c|c|c|c|c|}
\hline & Sens (\%) & Spec (\%) & Cut-off point & $\mathrm{OR}_{\mathrm{bin}} \ddagger$ & $95 \% \mathrm{Cl}$ & & $\mathrm{OR}_{\mathrm{z}} \S$ & $95 \% \mathrm{Cl}$ & \\
\hline \multicolumn{10}{|l|}{ MEN } \\
\hline \multicolumn{10}{|l|}{ All ethnicities ( $n$ 783) } \\
\hline BMI $\left(\mathrm{kg} / \mathrm{m}^{2}\right)$ & $64 \cdot 3$ & $64 \cdot 0$ & $27 \cdot 7$ & $2 \cdot 41$ & $1 \cdot 60,3 \cdot 62$ & a & $2 \cdot 13$ & $1 \cdot 59,2 \cdot 85$ & a \\
\hline WC $(\mathrm{cm})$ & $68 \cdot 4$ & $67 \cdot 9$ & $100 \cdot 0$ & $2 \cdot 95$ & $1 \cdot 95,4 \cdot 45$ & a & $2 \cdot 14$ & $1 \cdot 64,2 \cdot 79$ & a \\
\hline TtFM (of TBM) & $65 \cdot 0$ & $65 \cdot 0$ & $27 \cdot 8$ & $2 \cdot 34$ & $1.56,3.51$ & a & $1 \cdot 75$ & $1 \cdot 28,2 \cdot 40$ & a \\
\hline AmFM (of TFM) & $51 \cdot 0$ & $50 \cdot 9$ & $6 \cdot 7$ & $1 \cdot 13$ & $0.77,1.67$ & & $1 \cdot 06$ & $0 \cdot 82,1 \cdot 36$ & \\
\hline -LgFM (of TFM)\| & $61 \cdot 1$ & $61 \cdot 6$ & $33 \cdot 7$ & 0.49 & $0.33,0.74$ & a & $1 \cdot 61$ & $1 \cdot 25,2 \cdot 03$ & a \\
\hline TrFM (of TFM) & $63 \cdot 7$ & 63.5 & $54 \cdot 1$ & $2 \cdot 44$ & $1.62,3.67$ & a & 1.68 & $1 \cdot 32,2 \cdot 13$ & a \\
\hline RbFM (of TFM) & $63 \cdot 7$ & $63 \cdot 3$ & $21 \cdot 0$ & $2 \cdot 35$ & $1 \cdot 56,3.56$ & a & $1 \cdot 78$ & $1 \cdot 41,2 \cdot 25$ & a \\
\hline PIFM (of TFM) & $56 \cdot 0$ & $56 \cdot 1$ & $18 \cdot 3$ & $1 \cdot 60$ & $1 \cdot 08,2 \cdot 38$ & a & $1 \cdot 35$ & $1 \cdot 10,1 \cdot 66$ & a \\
\hline -SpFM (of TFM)\| & 53.5 & $53 \cdot 7$ & $13 \cdot 4$ & 0.69 & $0.47,1.02$ & $\mathrm{~b}$ & $1 \cdot 16$ & $0.96,1.41$ & \\
\hline \multicolumn{10}{|l|}{ Whites (n 330) } \\
\hline BMI $\left(\mathrm{kg} / \mathrm{m}^{2}\right)$ & $63 \cdot 6$ & $63 \cdot 7$ & $28 \cdot 7$ & $2 \cdot 72$ & $1 \cdot 51,4 \cdot 90$ & a & $2 \cdot 38$ & $1 \cdot 56,3 \cdot 62$ & a \\
\hline WC $(\mathrm{cm})$ & $68 \cdot 8$ & $67 \cdot 1$ & $104 \cdot 0$ & 4.03 & $2 \cdot 23,7 \cdot 27$ & a & $2 \cdot 82$ & $1 \cdot 86,4 \cdot 27$ & a \\
\hline TtFM (of TBM) & $62 \cdot 3$ & $62 \cdot 0$ & $28 \cdot 8$ & $2 \cdot 38$ & $1 \cdot 31,4 \cdot 30$ & a & $2 \cdot 01$ & $1 \cdot 22,3 \cdot 33$ & a \\
\hline AmFM (of TFM) & $53 \cdot 2$ & $53 \cdot 2$ & $6 \cdot 4$ & $1 \cdot 37$ & $0 \cdot 78,2 \cdot 42$ & & $1 \cdot 06$ & $0.71,1.59$ & \\
\hline -LgFM (of TFM)\| & $54 \cdot 6$ & $54 \cdot 8$ & $32 \cdot 5$ & 0.84 & $0 \cdot 48,1 \cdot 48$ & & 1.53 & $1 \cdot 11,2 \cdot 10$ & a \\
\hline TrFM (of TFM) & $62 \cdot 3$ & $62 \cdot 9$ & $56 \cdot 1$ & $2 \cdot 39$ & $1 \cdot 34,4 \cdot 26$ & a & $1 \cdot 72$ & $1 \cdot 22,2 \cdot 42$ & a \\
\hline RbFM (of TFM) & $57 \cdot 0$ & $57 \cdot 0$ & $21 \cdot 8$ & $1 \cdot 71$ & $0.96,3.06$ & $\mathrm{~b}$ & 1.93 & $1 \cdot 35,2 \cdot 75$ & a \\
\hline PIFM (of TFM) & $58 \cdot 4$ & $58 \cdot 2$ & $19 \cdot 0$ & $1 \cdot 77$ & $1 \cdot 00,3 \cdot 13$ & a & 1.56 & $1 \cdot 14,2 \cdot 13$ & $\mathrm{a}, \mathrm{c}$ \\
\hline -SpFM (of TFM)\| & $53 \cdot 2$ & $53 \cdot 6$ & $13 \cdot 4$ & 0.61 & $0.35,1.08$ & $\mathrm{~b}$ & $1 \cdot 26$ & $0.93,1.70$ & \\
\hline \multicolumn{10}{|c|}{ African-Americans ( $n$ 526) } \\
\hline BMI $\left(\mathrm{kg} / \mathrm{m}^{2}\right)$ & $62 \cdot 5$ & $62 \cdot 0$ & $27 \cdot 0$ & $2 \cdot 20$ & $1 \cdot 24,3 \cdot 91$ & a & 1.94 & $1 \cdot 28,2 \cdot 94$ & a \\
\hline WC $(\mathrm{cm})$ & $64 \cdot 1$ & $67 \cdot 2$ & $97 \cdot 0$ & $2 \cdot 71$ & $1 \cdot 52,4 \cdot 84$ & a & $1 \cdot 75$ & $1 \cdot 22,2 \cdot 53$ & a \\
\hline TtFM (of TBM) & $63 \cdot 7$ & $63 \cdot 8$ & $26 \cdot 1$ & $2 \cdot 12$ & $1 \cdot 20,3 \cdot 75$ & a & $1 \cdot 61$ & $1 \cdot 06,2 \cdot 45$ & a \\
\hline AmFM (of TFM) & $52 \cdot 5$ & $52 \cdot 6$ & $6 \cdot 9$ & $1 \cdot 10$ & $0.64,1.89$ & & $1 \cdot 06$ & $0 \cdot 76,1 \cdot 48$ & \\
\hline -LgFM (of TFM)\| & $65 \cdot 0$ & $65 \cdot 1$ & $34 \cdot 4$ & 0.39 & $0.22,0.68$ & a & $1 \cdot 70$ & $1 \cdot 20,2 \cdot 41$ & a \\
\hline TrFM (of TFM) & $63 \cdot 7$ & $63 \cdot 8$ & $53 \cdot 0$ & $2 \cdot 44$ & $1 \cdot 39,4 \cdot 29$ & a & 1.65 & $1 \cdot 17,2 \cdot 33$ & a \\
\hline RbFM (of TFM) & $63 \cdot 7$ & $63 \cdot 8$ & $20 \cdot 1$ & $2 \cdot 13$ & $1 \cdot 21,3 \cdot 75$ & a & 1.68 & $1 \cdot 22,2 \cdot 33$ & a \\
\hline PIFM (of TFM) & $51 \cdot 2$ & $51 \cdot 3$ & $17 \cdot 6$ & 1.08 & $0.62,1.89$ & & $1 \cdot 22$ & $0.91,1.62$ & \\
\hline -SpFM (of TFM)\| & $53 \cdot 7$ & $53 \cdot 8$ & $13 \cdot 4$ & 0.81 & $0 \cdot 47,1 \cdot 41$ & & $1 \cdot 08$ & $0 \cdot 83,1 \cdot 40$ & \\
\hline \multicolumn{10}{|l|}{ WOMEN } \\
\hline \multicolumn{10}{|l|}{ All ethnicities ( $n$ 1036) } \\
\hline BMI $\left(\mathrm{kg} / \mathrm{m}^{2}\right)$ & $60 \cdot 5$ & $60 \cdot 4$ & $31 \cdot 1$ & $1 \cdot 86$ & $1 \cdot 27,2 \cdot 72$ & a & $1 \cdot 40$ & $1 \cdot 19,1 \cdot 66$ & $\mathrm{a}, \mathrm{c}$ \\
\hline WC $(\mathrm{cm})$ & $63 \cdot 1$ & $64 \cdot 5$ & $103 \cdot 0$ & $2 \cdot 37$ & $1 \cdot 61,3 \cdot 47$ & a & 1.67 & $1 \cdot 36,2 \cdot 04$ & a \\
\hline TtFM (of TBM) & $56 \cdot 8$ & $56 \cdot 1$ & $45 \cdot 3$ & $1 \cdot 39$ & $0.96,2.02$ & $\mathrm{~b}$ & $1 \cdot 49$ & $1 \cdot 09,2.04$ & a \\
\hline AmFM (of TFM) & $54 \cdot 9$ & $54 \cdot 9$ & $7 \cdot 6$ & $1 \cdot 21$ & $0.84,1.76$ & & $1 \cdot 15$ & $0.98,1.36$ & \\
\hline -LgFM (of TFM) $\|$ & $58 \cdot 6$ & $58 \cdot 9$ & $36 \cdot 7$ & 0.64 & $0.44,0.92$ & a & $1 \cdot 50$ & $1 \cdot 24,1 \cdot 82$ & a \\
\hline TrFM (of TFM) & $59 \cdot 3$ & $59 \cdot 4$ & $49 \cdot 6$ & $1 \cdot 71$ & $1 \cdot 18,2 \cdot 47$ & a & $1 \cdot 50$ & $1 \cdot 23,1.84$ & a \\
\hline RbFM (of TFM) & $65 \cdot 4$ & $65 \cdot 4$ & $19 \cdot 6$ & $2 \cdot 88$ & $1 \cdot 97,4 \cdot 22$ & a & $2 \cdot 06$ & $1 \cdot 64,2 \cdot 59$ & a \\
\hline PIFM (of TFM) & $48 \cdot 8$ & $48 \cdot 9$ & $17 \cdot 2$ & 0.93 & $0.65,1.35$ & & $1 \cdot 02$ & $0 \cdot 85,1 \cdot 24$ & \\
\hline -SpFM (of TFM)\| & $47 \cdot 5$ & $47 \cdot 0$ & $11 \cdot 4$ & $1 \cdot 00$ & $0.69,1.45$ & & $1 \cdot 02$ & $0.83,1.25$ & \\
\hline \multicolumn{10}{|l|}{ Whites ( $n$ 440) } \\
\hline BMI $\left(\mathrm{kg} / \mathrm{m}^{2}\right)$ & $64 \cdot 2$ & $64 \cdot 2$ & $30 \cdot 5$ & $2 \cdot 85$ & $1 \cdot 53,5 \cdot 30$ & a & $1 \cdot 84$ & $1 \cdot 37,2 \cdot 47$ & a \\
\hline WC $(\mathrm{cm})$ & $70 \cdot 1$ & $67 \cdot 0$ & $103 \cdot 0$ & 3.50 & $1 \cdot 85,6 \cdot 64$ & a & $2 \cdot 23$ & $1 \cdot 60,3 \cdot 11$ & a \\
\hline TtFM (of TBM) & $55 \cdot 2$ & $55 \cdot 3$ & $44 \cdot 6$ & $1 \cdot 24$ & $0 \cdot 68,2 \cdot 27$ & & $1 \cdot 73$ & $1 \cdot 02,2 \cdot 94$ & a \\
\hline AmFM (of TFM) & $52 \cdot 2$ & $52 \cdot 2$ & $7 \cdot 2$ & 1.04 & $0.58,1 \cdot 85$ & & $1 \cdot 14$ & $0.88,1.49$ & \\
\hline -LgFM (of TFM)\| & $58 \cdot 2$ & $58 \cdot 4$ & $36 \cdot 2$ & 0.62 & $0 \cdot 35,1 \cdot 10$ & & 1.63 & $1 \cdot 20,2 \cdot 22$ & a \\
\hline TrFM (of TFM) & $58 \cdot 2$ & $58 \cdot 1$ & $50 \cdot 8$ & $1 \cdot 71$ & $0 \cdot 95,3 \cdot 10$ & b & $1 \cdot 69$ & $1 \cdot 21,2 \cdot 34$ & a \\
\hline RbFM (of TFM) & $65 \cdot 7$ & $66 \cdot 5$ & $20 \cdot 1$ & $4 \cdot 10$ & $2 \cdot 19,7 \cdot 66$ & a & $2 \cdot 14$ & $1.50,3.05$ & a \\
\hline PIFM (of TFM) & $49 \cdot 2$ & $48 \cdot 6$ & $17 \cdot 7$ & 0.86 & $0.48,1.55$ & & $1 \cdot 22$ & $0.91,1.62$ & \\
\hline -SpFM (of TFM)\| & $47 \cdot 8$ & $47 \cdot 2$ & $11 \cdot 7$ & $1 \cdot 18$ & $0 \cdot 65,2 \cdot 15$ & & 0.80 & $0.57,1.40$ & \\
\hline \multicolumn{10}{|c|}{ African-Americans ( $n$ 670) } \\
\hline BMI $\left(\mathrm{kg} / \mathrm{m}^{2}\right)$ & $57 \cdot 8$ & $57 \cdot 6$ & $31 \cdot 6$ & $1 \cdot 37$ & $0.83,2 \cdot 28$ & & $1 \cdot 23$ & $1 \cdot 01,1 \cdot 49$ & a \\
\hline WC (cm) & $61 \cdot 3$ & $61 \cdot 0$ & $102 \cdot 0$ & $1 \cdot 81$ & $1 \cdot 09,3 \cdot 00$ & a & $1 \cdot 37$ & $1 \cdot 05,1 \cdot 78$ & a \\
\hline TtFM (of TBM) & $54 \cdot 7$ & $54 \cdot 8$ & $45 \cdot 6$ & $1 \cdot 08$ & $0.66,1.79$ & & $1 \cdot 33$ & $0 \cdot 89,2 \cdot 00$ & \\
\hline AmFM (of TFM) & $56 \cdot 8$ & $56 \cdot 8$ & $8 \cdot 0$ & $1 \cdot 26$ & $0 \cdot 77,2 \cdot 07$ & & $1 \cdot 16$ & $0.93,1.43$ & \\
\hline -LgFM (of TFM) $\|$ & $60 \cdot 0$ & $60 \cdot 1$ & $37 \cdot 2$ & 0.63 & $0.38,1.03$ & $\mathrm{~b}$ & $1 \cdot 41$ & $1 \cdot 09,1 \cdot 83$ & a \\
\hline TrFM (of TFM) & $61 \cdot 0$ & $60 \cdot 8$ & $49 \cdot 0$ & $2 \cdot 00$ & $1 \cdot 22,3 \cdot 26$ & a & $1 \cdot 39$ & $1 \cdot 05,1 \cdot 82$ & a \\
\hline RbFM (of TFM) & $65 \cdot 3$ & $65 \cdot 1$ & $19 \cdot 5$ & $2 \cdot 51$ & $1 \cdot 51,4 \cdot 18$ & a & $2 \cdot 04$ & $1 \cdot 49,2 \cdot 81$ & a \\
\hline PIFM (of TFM) & $48 \cdot 5$ & $48 \cdot 6$ & $16 \cdot 8$ & 0.94 & $0.57,1.54$ & & $1 \cdot 01$ & $0 \cdot 74,1 \cdot 40$ & \\
\hline -SpFM (of TFM)\| & $49 \cdot 5$ & $48 \cdot 4$ & $11 \cdot 1$ & 0.89 & $0.55,1.45$ & & $1 \cdot 17$ & $0.89,1.54$ & \\
\hline
\end{tabular}

MetS, metabolic syndrome; HANDLS, Healthy Aging in Neighborhoods of Diversity Across the Life Span; Sens, sensitivity; Spec, specificity; WC, waist circumference; TtFM; percentage total body fat mass; TBM, total body mass; AmFM, percentage arm fat mass; TFM, total fat mass; LgFM, percentage leg fat mass; TrFM, percentage trunk fat mass; RbFM, percentage rib fat mass; PIFM, percentage pelvic fat mass; SpFM, percentage spine fat mass.

a $P<0.05$ for the null hypothesis that $\log _{\mathrm{e}}(\mathrm{OR})=0$.

${ }^{\mathrm{b}} P<0 \cdot 10$ for the null hypothesis that $\log _{\mathrm{e}}(\mathrm{OR})=0$.

${ }^{c} P<0.05$ for the null hypothesis that $\log _{e}(O R)_{\text {men }}=\log _{e}(O R)_{\text {women }}$

tSee Table 1, footnote $\neq$, for details on MetS (definition 2).

fOR were derived from a multivariate logistic regression model with binary outcome being MetS (definition 2 , yes $=1$, no $=0$ ), main exposure being binary body fat or anthropometric index ( $>$ cut-off $=1 \mathrm{v}$. $\leq$ cut-off $=0$ ) and potential confounding factors adjusted for including age, race/ethnicity, poverty status, education level, marital status, smoking status and use of medications related to MetS. LgFM and SpFM were not multiplied by -1 in this particular analysis. $\S O R$ were derived from a multivariate logistic regression model with binary outcome being MetS (definition 2 , yes $=1$, no $=0$ ), main exposure being binary body fat or anthropometric index (standardized Z-score) and potential confounding factors adjusted for including age, race/ethnicity, poverty status, education level, marital status, smoking status and use of medications related to MetS.

$\|$ Sens and Spec values were obtained based on a ROC curve analysis in which LgFM and SpFM observed values were multiplied by -1 . 
of percentage total body fat with BMI and/or $\operatorname{WC}^{(13,14,16,17,23,24,27)}$, while contradicting others ${ }^{(18,19,40)}$. However, most of these studies used either bioelectrical impedance or densitometry. Compared with DEXA, these assays may have larger systematic and random measurement errors potentially causing discrepancies in findings. Most studies used either Pearson's correlation or stepwise regression models when outcomes were continuous (e.g. HDL-C), whereas some compared hazard or incidence rate ratios or adjusted odds ratios across adiposity predictors for a single binary outcome (e.g. incident type 2 diabetes or all-cause mortality) ${ }^{(13-15,17,20-24,27,28,41,42)}$. Among the few that conducted ROC curve analysis with MetS or type 2 diabetes as the outcome, AUC ranged between 0.65 and $0 \cdot 85$ (usually close to $0 \cdot 70$ ) for all anthropometric measures considered as well as percentage body fat ${ }^{(16,17,24-26,28,43-45)}$.

The debate as to whether WC is superior to other anthropometric indices is ongoing. In one of these studies, WC was superior to waist:hip ratio but similar to BMI in predicting type 2 diabetes $^{(28)}$, while in another waist:height ratio and BMI were consistently the best predictors of this health outcome among men and women $^{(21)}$. Finally, percentage body fat and waist:hip ratio quintiles were superior to BMI in predicting allcause mortality in a large Swedish cohort, although their predictive power varied by sex and age group ${ }^{(40)}$.

Second, there were several important findings related to regional adiposity. In fact, comparing TtFM with other region-specific body fat indices, the only index significantly superior was RbFM among women (AfricanAmericans in particular) for MetS (definition 2) and the two dyslipidaemia components of MetS (HDL-C and TAG), even though it was comparable to WC. Among men, none of the region-specific body fat indices was superior to TtFM. One important finding which was not replicated elsewhere was that LgFM was protective against MetS and its components, particularly among African-American men. This may be due to the inverse and strong association of LgFM with TrFM (Pearson's correlation ranged between -0.92 and $-0.94, P<0.05$; see Appendix 1).

Third, there were clear sex and race differences in the predictive values of various anthropometric and DEXAderived measures. For instance, comparing TtFM to WC in predicting MetS (definition 2), the predictive value was not significantly different among African-American men but was poorer among all other sex and ethnic groups. This is an important finding not replicated thus far by others (e.g. reference (24)). Additionally, we found BMI to be inferior to WC among men in general and white men in particular for MetS (definition 2) prediction, but not women. This general finding, which is indicative of the lower value of BMI compared with WC, is consistent with other reports that compared BMI and $\mathrm{WC}$ in their predictive value of MetS components or type 2 diabetes $^{(20,28,44)}$, but not with others ${ }^{(23,42)}$.
Fourth, based on ROC curve analyses with MetS (definition 2) as the target outcome, we estimated optimal cut-off points for each adiposity index. We found, among others, that WC cut-off points varied across race-sex groups, between $97 \cdot 0 \mathrm{~cm}$ among African-American men and $104.0 \mathrm{~cm}$ among white men, with women having an optimal cut-point of $103.0 \mathrm{~cm}$. These cut-off points were also disparate from those recommended by the National Institutes of Health/North American Association for the Study of Obesity report of $88 \mathrm{~cm}$ among women and $102 \mathrm{~cm}$ among men ${ }^{(35)}$, highlighting the need for sex- and race-specific cut-off points as was suggested previously by others ${ }^{(46)}$.

Finally, our sensitivity analysis indicated that combining all measures together rather than screening for each one separately may increase AUC by $11-12 \%$ of its original value in which only BMI and WC binary variables are considered for prediction of MetS (definition 2). Thus, whenever available, DEXA measures can be used in combination with WC and BMI to improve prediction of MetS.

Our study has several notable strengths. First, to our knowledge, it is the first large study to assess the predictive value of percentage total and regional body fatness (using DEXA scans) and compare it to commonly used anthropometric measurements when the outcomes of interest are MetS and its component risk factors. Second, it is also one of few to systematically compare AUC using statistical tests rather than visually comparing point graphical presentations and point estimates. Third, the inclusion of several metabolic risk factors as outcomes allowed us to differentiate the predictive values of each body fat and anthropometric index across those risk factors and to simultaneously examine sex differences.

Despite its strengths, our study has several limitations. First, it is a cross-sectional study, thus precluding ascertainment of temporality in many of the adiposity-metabolic associations. However, the original NCEP ATP III definition (1), and based on previous prospective cohort studies $^{(47,48)}$, assumes that obesity precedes the development of other components of MetS. Other limitations include selection bias due to attrition between the initial household survey and the MRV examination, which led the available sample to be significantly older than the original selected household sample, with a higher proportion of females and a higher percentage of participants with low income. Moreover, different DEXA equipment (Hologic) was used for those who were morbidly obese, data that were unavailable at the time of the study. In fact, DEXA scans were less accurate at higher BMI levels, in part due to truncal adiposity, and older persons were more likely to be excluded for DEXA scans in general than their younger counterparts. It is worth noting that although DEXA is nowadays considered as one of the most accurate methods of measuring body composition (including percentage total and regional body), it was 
initially designed to clinically diagnose osteoporosis, i.e. for bone density measurement ${ }^{(49)}$. Additionally, our data included fewer white men than other groups, which made comparisons across sex-race groups less reliable and low-powered. Finally, HANDLS baseline data did not include measures of physical activity, which is potentially an important confounder or effect modifier in the relationship between adiposity and metabolic disorders.

In conclusion, the present study provides additional evidence that WC is among the most powerful tools to predict MetS and its non-obesity related components. Moreover, TtFM in most cases had no additional advantage for both men and women. In one instance, however, RbFM (fat concentration in the ribs region) was superior to both TtFM and WC among women in predicting dyslipidaemia-TAG and superior to TtFM in predicting MetS and dyslipidaemia-HDL-C. Its higher predictive value over TtFM for MetS was mostly noted among AfricanAmerican women. In particular, a value of RbFM over $20 \%$ was highly predictive of MetS for both sexes. In contrast, LgFM was protective against MetS with an optimal cut-off point of $34 \%$ among men and $37 \%$ among women. Thus, WC should continue to define the obesity components of MetS, even though RbFM among women and LgFM for both sexes may have additional predictive value. Thus, our findings may help guide screening and preventive efforts to alleviate the obesity epidemic and its related metabolic disturbances in the USA, particularly in diverse populations of low to middle socio-economic status within urban neighbourhoods.

\section{Acknowledgements}

This research was supported entirely by the Intramural Research Program of the National Institutes of Health, National Institute on Aging. The authors declare no conflicts of interest. The authors' contributions were as follows. M.A.B.: conceptualization, full data access, data management, statistical analysis, literature review, write-up of the manuscript, revision of the manuscript. M.T.F.K.: literature review, write-up of parts of the manuscript, revision of the manuscript. Y.W.: literature review, help with statistical methods, revision of the manuscript. M.A.M.: data management, revision of the manuscript. M.K.E.: data acquisition, revision of the manuscript. A.B.Z.: data acquisition, write-up of parts of the manuscript, revision of the manuscript. The authors would like to thank Drs Jitka Sojkova and Lori L. Beason-Held for their internal review of the manuscript.

\section{References}

1. National Institutes of Health (2001) Third Report of the National Cholesterol Education Program Expert Panel on Detection, Evaluation, and Treatment of High Blood
Cholesterol in Adults (Adult Treatment Panel III). Executive Summary. Bethesda, MD: NIH.

2. Ford ES (2005) Risks for all-cause mortality, cardiovascular disease, and diabetes associated with the metabolic syndrome: a summary of the evidence. Diabetes Care $\mathbf{2 8}$, $1769-1778$.

3. Qiao Q (2006) Comparison of different definitions of the metabolic syndrome in relation to cardiovascular mortality in European men and women. Diabetologia 49, 2837-2846.

4. Thomas GN, Schooling CM, McGhee SM et al. (2007) Metabolic syndrome increases all-cause and vascular mortality: the Hong Kong Cardiovascular Risk Factor Study. Clin Endocrinol (Oxf) 66, 666-671.

5. Wassink AM, van der Graaf Y, Olijhoek JK et al. (2008) Metabolic syndrome and the risk of new vascular events and all-cause mortality in patients with coronary artery disease, cerebrovascular disease, peripheral arterial disease or abdominal aortic aneurysm. Eur Heart J 29, 213-223.

6. Lazarus R, Baur L, Webb K et al. (1996) Body mass index in screening for adiposity in children and adolescents: systematic evaluation using receiver operating characteristic curves. Am J Clin Nutr 63, 500-506.

7. Sardinha LB, Going SB, Teixeira PJ et al. (1990) Receiver operating characteristic analysis of body mass index, triceps skinfold thickness, and arm girth for obesity screening in children and adolescents. Am J Clin Nutr $\mathbf{7 0}$, 1090-1095.

8. Taylor RW, Jones IE, Williams SM et al. (2000) Evaluation of waist circumference, waist-to-hip ratio, and the conicity index as screening tools for high trunk fat mass, as measured by dual-energy X-ray absorptiometry, in children aged 3-19 y. Am J Clin Nutr 72, 490-495.

9. Mei Z, Grummer-Strawn LM, Pietrobelli A et al. (2002) Validity of body mass index compared with other bodycomposition screening indexes for the assessment of body fatness in children and adolescents. Am J Clin Nutr 75, 978-985.

10. Taylor RW, Keil D, Gold EJ et al. (1998) Body mass index, waist girth, and waist-to-hip ratio as indexes of total and regional adiposity in women: evaluation using receiver operating characteristic curves. Am J Clin Nutr 67, 44-49.

11. Evans EM, Rowe DA, Racette SB et al. (2006) Is the current BMI obesity classification appropriate for black and white postmenopausal women? Int J Obes (Lond) 30, 837-843.

12. Svendsen OL (2003) Should measurement of body composition influence therapy for obesity? Acta Diabetol $\mathbf{4 0}$, Suppl. 1, S250-S253.

13. Richelsen B \& Pedersen SB (1995) Associations between different anthropometric measurements of fatness and metabolic risk parameters in non-obese, healthy, middleaged men. Int J Obes Relat Metab Disord 19, 169-174.

14. Tai ES, Ho SC, Fok AC et al. (1999) Measurement of obesity by anthropometry and bioelectric impedance analysis: correlation with fasting lipids and insulin resistance in an Asian population. Ann Acad Med Singapore 28, 445-450.

15. Nakanishi N, Nakamura K, Suzuki K et al. (2000) Associations of body mass index and percentage body fat by bioelectrical impedance analysis with cardiovascular risk factors in Japanese male office workers. Ind Health $\mathbf{3 8}$, 273-279.

16. Warne DK, Charles MA, Hanson RL et al. (1995) Comparison of body size measurements as predictors of NIDDM in Pima Indians. Diabetes Care 18, 435-439.

17. Tulloch-Reid MK, Williams DE, Looker HC et al. (2003) Do measures of body fat distribution provide information on the risk of type 2 diabetes in addition to measures of general obesity? Comparison of anthropometric predictors of type 2 diabetes in Pima Indians. Diabetes Care 26, 2556-2561. 
18. Nagaya T, Yoshida H, Takahashi H et al. (1999) Body mass index (weight/height ${ }^{2}$ ) or percentage body fat by bioelectrical impedance analysis: which variable better reflects serum lipid profile? Int J Obes Relat Metab Disord 23, 771-774.

19. De Lorenzo F, Mukherjee M, Kadziola Z et al. (1998) Association of overall adiposity rather than body mass index with lipids and procoagulant factors. Thromb Haemost 80, 603-606.

20. Reeder BA, Senthilselvan A, Despres JP et al. (1997) The association of cardiovascular disease risk factors with abdominal obesity in Canada. Canadian Heart Health Surveys Research Group. CMAJ 157, Suppl. 1, S39-S45.

21. Rissanen P, Hamalainen P, Vanninen E et al. (1997) Relationship of metabolic variables to abdominal adiposity measured by different anthropometric measurements and dual-energy X-ray absorptiometry in obese middle-aged women. Int J Obes Relat Metab Disord 21, 367-371.

22. von Eyben FE, Mouritsen E, Holm J et al. (2003) Intraabdominal obesity and metabolic risk factors: a study of young adults. Int J Obes Relat Metab Disord 27, 941-949.

23. Wannamethee SG, Shaper AG, Morris RW et al. (2005) Measures of adiposity in the identification of metabolic abnormalities in elderly men. Am J Clin Nutr $\mathbf{8 1}$, 1313-1321.

24. Bosy-Westphal A, Geisler C, Onur S et al. (2006) Value of body fat mass vs anthropometric obesity indices in the assessment of metabolic risk factors. Int J Obes (Lond) $\mathbf{3 0}$, 475-483.

25. Hyun YJ, Kim OY, Jang Y et al. (2008) Evaluation of metabolic syndrome risk in Korean premenopausal women: not waist circumference but visceral fat. Circ J 72, 1308-1315.

26. Lee K, Lee S \& Kim YJ (2008) Waist circumference, dualenergy X-ray absorptiometrically measured abdominal adiposity, and computed tomographically derived intraabdominal fat area on detecting metabolic risk factors in obese women. Nutrition 24, 625-631.

27. Bray GA, Jablonski KA, Fujimoto WY et al. (2008) Relation of central adiposity and body mass index to the development of diabetes in the Diabetes Prevention Program. AmJ Clin Nutr 87, 1212-1218.

28. Wang Y, Rimm EB, Stampfer MJ et al. (2005) Comparison of abdominal adiposity and overall obesity in predicting risk of type 2 diabetes among men. Am J Clin Nutr 81, $555-563$.

29. Grundy SM, Cleeman JI, Daniels SR et al. (2005) Diagnosis and management of the metabolic syndrome: an American Heart Association/National Heart, Lung, and Blood Institute Scientific Statement. Circulation 112, 2735-2752.

30. Zhu S, Wang Z, Shen W et al. (2003) Percentage body fat ranges associated with metabolic syndrome risk: results based on the third National Health and Nutrition Examination Survey (1988-1994). Am J Clin Nutr 78, 228-235.

31. Wallace TM, Levy JC \& Matthews DR (2004) Use and abuse of HOMA modeling. Diabetes Care 27, 1487-1495.

32. Matthews DR, Hosker JP, Rudenski AS et al. (1985) Homeostasis model assessment: insulin resistance and beta-cell function from fasting plasma glucose and insulin concentrations in man. Diabetologia 28, 412-419.
33. Anon (2003) Handbook of Diagnostic Tests, 3rd ed. Philadelphia, PA: Lippincott, Williams \& Wilkins.

34. Ridker PM, Cushman M, Stampfer MJ et al. (1997) Inflammation, aspirin, and the risk of cardiovascular disease in apparently healthy men. $N$ Engl J Med 336, 973-979.

35. National Institutes of Health, National Heart, Lung, and Blood Institute \& North American Association for the Study of Obesity (2000) The Practical Guide: Identification, Evaluation, and Treatment of Overweight and Obesity in Adults. Bethesda, MD: NIH.

36. World Health Organization (1979) The ICD-9 Classification of Mental and Behavioral Disorders: Diagnostic Criteria for Research. Geneva: WHO.

37. Albeck MJ \& Borgesen SE (1990) ROC-curve analysis. A statistical method for the evaluation of diagnostic tests. Ugeskr Laeger 152, 1650-1653.

38. Soreide K (2009) Receiver-operating characteristic (ROC) curve analysis in diagnostic, prognostic and predictive biomarker research. J Clin Pathol 62, 1-5.

39. DeLong ER, DeLong DM \& Clarke-Pearson DL (1988) Comparing the areas under two or more correlated receiver operating characteristic curves: a nonparametric approach. Biometrics 44, 837-845.

40. Lahmann PH, Lissner L, Gullberg B et al. (2002) A prospective study of adiposity and all-cause mortality: the Malmo Diet and Cancer Study. Obes Res 10, 361-369.

41. Vazquez G, Duval S, Jacobs Jr DR et al. (2007) Comparison of body mass index, waist circumference, and waist/hip ratio in predicting incident diabetes: a meta-analysis. Epidemiol Rev 29, 115-128.

42. Meisinger C, Doring A, Thorand B et al. (2006) Body fat distribution and risk of type 2 diabetes in the general population: are there differences between men and women? The MONICA/KORA Augsburg cohort study. Am J Clin Nutr 84, 483-489.

43. Woo J, Ho SC, Yu AL et al. (2002) Is waist circumference a useful measure in predicting health outcomes in the elderly? Int J Obes Relat Metab Disord 26, 1349-1355.

44. Moreno LA, Pineda I, Rodriguez G et al. (2002) Waist circumference for the screening of the metabolic syndrome in children. Acta Paediatr 91, 1307-1312.

45. Bouguerra R, Alberti H, Smida H et al. (2007) Waist circumference cut-off points for identification of abdominal obesity among the Tunisian adult population. Diabetes Obes Metab 9, 859-868.

46. Ness-Abramof R \& Apovian CM (2008) Waist circumference measurement in clinical practice. Nutr Clin Pract 23, 397-404.

47. Maison P, Byrne CD, Hales CN et al. (2001) Do different dimensions of the metabolic syndrome change together over time? Evidence supporting obesity as the central feature. Diabetes Care 24, 1758-1763.

48. Palaniappan L, Carnethon MR, Wang Y et al. (2004) Predictors of the incident metabolic syndrome in adults: the Insulin Resistance Atherosclerosis Study. Diabetes Care 27, 788-793.

49. Andreoli A, Scalzo G, Masala S et al. (2009) Body composition assessment by dual-energy X-ray absorptiometry (DXA). Radiol Med 114, 286-300. 
Appendix 1

Pearson's correlation between adiposity indices: HANDLS study (n 1935)

\begin{tabular}{|c|c|c|c|c|c|c|c|c|c|}
\hline & WC & TtFM & BMI & AmFM & LgFM & TrFM & $\mathrm{RbFM}$ & PIFM & SpFM \\
\hline \multicolumn{10}{|c|}{ White men ( $n$ 327) } \\
\hline WC & 1 & & & & & & & & \\
\hline TtFM & $0.62^{*}$ & 1 & & & & & & & \\
\hline BMI & $0 \cdot 65^{*}$ & $0.74^{*}$ & 1 & & & & & & \\
\hline AmFM & $0 \cdot 20^{*}$ & $0 \cdot 29^{*}$ & $0 \cdot 20^{*}$ & 1 & & & & & \\
\hline LgFM & $-0.21^{*}$ & -0.04 & -0.09 & -0.09 & 1 & & & & \\
\hline TrFM & $0 \cdot 23^{*}$ & 0.07 & $0 \cdot 16^{*}$ & $-0 \cdot 17^{\star}$ & $-0.94^{*}$ & 1 & & & \\
\hline RbFM & $0 \cdot 45^{\star}$ & $0 \cdot 41^{*}$ & $0.51^{*}$ & $0 \cdot 24^{*}$ & $-0 \cdot 65^{\star}$ & $0 \cdot 65^{\star}$ & 1 & & \\
\hline PIFM & 0.02 & $-0 \cdot 16^{*}$ & 0.00 & $-0 \cdot 37^{\star}$ & $-0 \cdot 59^{*}$ & $0 \cdot 67^{*}$ & 0.06 & 1 & \\
\hline SpFM & $-0 \cdot 18^{*}$ & $-0 \cdot 29^{*}$ & $-0 \cdot 42^{*}$ & $-0 \cdot 26^{*}$ & $-0 \cdot 42^{*}$ & $0.44^{*}$ & $-0 \cdot 14^{*}$ & $0 \cdot 17^{*}$ & 1 \\
\hline \multicolumn{10}{|c|}{ African-American men ( $n$ 511) } \\
\hline WC & 1 & & & & & & & & \\
\hline TtFM & $0 \cdot 75^{\star}$ & 1 & & & & & & & \\
\hline BMI & $0 \cdot 84^{*}$ & $0.73^{*}$ & 1 & & & & & & \\
\hline AmFM & $0 \cdot 12^{*}$ & $0 \cdot 15^{\star}$ & $0 \cdot 10^{*}$ & 1 & & & & & \\
\hline LgFM & $-0 \cdot 13^{\star}$ & $-0 \cdot 11^{*}$ & $-0.09^{*}$ & -0.02 & 1 & & & & \\
\hline TrFM & $0 \cdot 24^{*}$ & $0 \cdot 20^{*}$ & $0 \cdot 21^{*}$ & $-0 \cdot 27^{\star}$ & $-0 \cdot 92^{*}$ & 1 & & & \\
\hline RbFM & $0 \cdot 50^{\star}$ & $0.56^{\star}$ & $0.55^{\star}$ & $0 \cdot 21^{*}$ & $-0 \cdot 54^{*}$ & $0.57^{*}$ & 1 & & \\
\hline PIFM & -0.02 & $-0 \cdot 08^{\star}$ & -0.00 & $-0 \cdot 48^{*}$ & $-0 \cdot 54^{*}$ & $0 \cdot 65^{\star}$ & 0.04 & 1 & \\
\hline SpFM & $-0 \cdot 36^{\star}$ & $-0 \cdot 40^{*}$ & $-0 \cdot 46^{*}$ & $-0 \cdot 28^{*}$ & $-0 \cdot 37^{*}$ & $0 \cdot 34^{*}$ & $-0 \cdot 31^{*}$ & $0 \cdot 17^{*}$ & 1 \\
\hline \multicolumn{10}{|c|}{ White women ( $n$ 438) } \\
\hline WC & 1 & & & & & & & & \\
\hline TtFM & $0 \cdot 66^{*}$ & 1 & & & & & & & \\
\hline BMI & $0 \cdot 86^{*}$ & $0 \cdot 76^{\star}$ & 1 & & & & & & \\
\hline AmFM & $0 \cdot 43^{\star}$ & $0 \cdot 45^{\star}$ & $0 \cdot 45^{\star}$ & 1 & & & & & \\
\hline LgFM & $-0 \cdot 29^{\star}$ & $-0 \cdot 17^{*}$ & $-0 \cdot 19^{\star}$ & $-0 \cdot 31^{*}$ & 1 & & & & \\
\hline TrFM & $0 \cdot 25^{*}$ & $0 \cdot 15^{\star}$ & $0 \cdot 15^{\star}$ & -0.01 & $-0 \cdot 93^{*}$ & 1 & & & \\
\hline RbFM & $0.54^{\star}$ & $0 \cdot 46^{\star}$ & $0.50^{*}$ & $0 \cdot 38^{\star}$ & $-0 \cdot 76^{\star}$ & $0 \cdot 73^{\star}$ & 1 & & \\
\hline PIFM & -0.09 & $-0 \cdot 19^{*}$ & $-0 \cdot 14^{\star}$ & $-0 \cdot 35^{\star}$ & $-0.52^{*}$ & $0 \cdot 63^{*}$ & 0.08 & 1 & \\
\hline SpFM & $-0 \cdot 14^{\star}$ & $-0 \cdot 15$ & $-0 \cdot 27^{\star}$ & $-0 \cdot 21^{*}$ & $-0 \cdot 50^{*}$ & $0 \cdot 59^{\star}$ & $0 \cdot 12^{*}$ & $0 \cdot 29^{*}$ & 1 \\
\hline \multicolumn{10}{|c|}{ African-American women ( $n$ 659) } \\
\hline WC & 1 & & & & & & & & \\
\hline TtFM & $0 \cdot 62^{*}$ & 1 & & & & & & & \\
\hline BMI & $0 \cdot 72^{*}$ & $0 \cdot 72^{*}$ & 1 & & & & & & \\
\hline AmFM & $0 \cdot 38^{\star}$ & $0.47^{\star}$ & $0.44^{*}$ & 1 & & & & & \\
\hline LgFM & $-0 \cdot 22^{*}$ & $-0 \cdot 13^{*}$ & $-0 \cdot 12^{*}$ & $-0.24^{*}$ & 1 & & & & \\
\hline TrFM & $0 \cdot 19^{*}$ & $0 \cdot 11^{*}$ & $0.07^{*}$ & $-0 \cdot 08^{*}$ & $-0.92^{*}$ & 1 & & & \\
\hline RbFM & $0 \cdot 48^{*}$ & $0.44^{*}$ & $0.43^{*}$ & $0.38^{*}$ & $-0 \cdot 71^{*}$ & $0 \cdot 67^{*}$ & 1 & & \\
\hline PIFM & 0.02 & -0.05 & -0.05 & $-0 \cdot 36^{\star}$ & $-0.58^{\star}$ & $0 \cdot 709^{*}$ & $0 \cdot 12^{*}$ & 1 & \\
\hline SpFM & $-0 \cdot 28^{\star}$ & $-0 \cdot 34^{*}$ & $-0.41^{*}$ & $-0 \cdot 26^{\star}$ & $-0.42^{*}$ & $0.50^{\star}$ & -0.03 & $0.22^{*}$ & 1 \\
\hline
\end{tabular}

HANDLS, Healthy Aging in Neighborhoods of Diversity Across the Life Span; WC, waist circumference; TtFM; percentage total body fat mass; AmFM, percentage arm fat mass; LgFM, percentage leg fat mass; TrFM, percentage trunk fat mass; RbFM, percentage rib fat mass; PIFM, percentage pelvic fat mass; SpFM, percentage spine fat mass.

${ }^{*} P<0.05$ for the null hypothesis that Pearson's correlation coefficient $r=0$. 
Appendix 2

AUC (95\% CI) for MetS (definition 2) † and metabolic risk factors predicted by adiposity indices, stratified by sex and race: HANDLS study

\begin{tabular}{|c|c|c|c|c|c|c|}
\hline & \multicolumn{3}{|c|}{ White men ( $n$ 314) $\ddagger$} & \multicolumn{3}{|c|}{ White women $(n$ 425) $\ddagger$} \\
\hline & AUC & $95 \% \mathrm{Cl}$ & & AUC & $95 \% \mathrm{Cl}$ & \\
\hline \multicolumn{7}{|l|}{ MetS (definition 2)† } \\
\hline BMI $\left(\mathrm{kg} / \mathrm{m}^{2}\right)$ & 0.689 & $0.623,0.754$ & a & 0.695 & $0.629,0.761$ & $b$ \\
\hline WC $(\mathrm{cm})$ & 0.739 & $0.680,0.799$ & $\mathrm{~b}$ & 0.733 & $0.670,0.795$ & $\mathrm{~b}$ \\
\hline TtFM (of TBM) & 0.659 & $0.595,0.722$ & a & 0.605 & $0.540,0.670$ & $\mathrm{a}$ \\
\hline AmFM (of TFM) & 0.518 & $0.442,0.595$ & $a, b$ & 0.568 & $0.497,0.639$ & $\mathrm{a}$ \\
\hline -LgFM (of TFM) § & 0.626 & $0.554,0.697$ & & 0.641 & $0.566,0.716$ & \\
\hline TrFM (of TFM) & 0.649 & $0.577,0.721$ & & 0.643 & $0.566,0.716$ & \\
\hline RbFM (of TFM) & 0.636 & $0.568,0.703$ & a & 0.694 & $0.627,0.760$ & \\
\hline PIFM (of TFM) & 0.630 & $0.559,0.700$ & & 0.506 & $0.428,0.585$ & a \\
\hline -SpFM (of TFM)§ & 0.552 & $0.478,0.625$ & a & 0.439 & $0.355,0.522$ & $a, b$ \\
\hline \multicolumn{7}{|c|}{ Blood pressure NCEP componentt } \\
\hline $\mathrm{BMI}\left(\mathrm{kg} / \mathrm{m}^{2}\right)$ & 0.584 & $0.519,0.648$ & & 0.589 & $0.524,0.654$ & \\
\hline WC $(\mathrm{cm})$ & 0.625 & $0.561,0.689$ & & 0.606 & $0.544,0.669$ & \\
\hline TtFM (of TBM) & 0.596 & $0.532,0.660$ & & 0.561 & $0.498,0.624$ & \\
\hline AmFM (of TFM) & 0.507 & $0.469,0.575$ & & 0.551 & $0.487,0.615$ & \\
\hline -LgFM (of TFM)§ & 0.569 & $0.503,0.635$ & & 0.631 & $0.567,0.694$ & \\
\hline TrFM (of TFM) & 0.576 & $0.509,0.642$ & & 0.628 & $0.561,0.693$ & \\
\hline RbFM (of TFM) & 0.549 & $0.483,0.616$ & & 0.605 & $0.542,0.668$ & \\
\hline PIFM (of TFM) & 0.553 & $0.485,0.620$ & & 0.569 & $0.501,0.637$ & \\
\hline -SpFM (of TFM)§ & 0.475 & $0.406,0.546$ & $a, b$ & 0.380 & $0.314,0.446$ & $a, b$ \\
\hline \multicolumn{7}{|c|}{ Fasting glucose NCEP component } \\
\hline BMI $\left(\mathrm{kg} / \mathrm{m}^{2}\right)$ & 0.684 & $0.608,0 \cdot 760$ & & 0.739 & $0.680,0.797$ & $b$ \\
\hline WC $(\mathrm{cm})$ & 0.686 & $0.609,0.763$ & & 0.772 & $0.718,0.826$ & $\mathrm{~b}$ \\
\hline TtFM (of TBM) & 0.623 & $0.547,0.699$ & & 0.648 & $0.586,0.711$ & $\mathrm{a}$ \\
\hline AmFM (of TFM) & 0.548 & $0.467,0.629$ & a & 0.618 & $0.550,0.685$ & a \\
\hline -LgFM (of TFM)§ & 0.583 & $0.497,0.669$ & & 0.603 & $0.534,0.673$ & a \\
\hline TrFM (of TFM) & 0.595 & $0.509,0.681$ & & 0.597 & $0.524,0.668$ & a \\
\hline RbFM (of TFM) & 0.612 & $0.534,0.691$ & & 0.672 & $0.611,0.734$ & $\mathrm{a}$ \\
\hline PIFM (of TFM) & 0.571 & $0.488,0.655$ & & 0.458 & $0.388,0.528$ & $a, b$ \\
\hline -SpFM (of TFM)§ & 0.561 & $0.479,0.642$ & & 0.468 & $0.386,0.549$ & $a, b$ \\
\hline \multicolumn{7}{|c|}{ Dyslipidaemia-TAG NCEP component† } \\
\hline BMI $\left(\mathrm{kg} / \mathrm{m}^{2}\right)$ & 0.682 & $0.623,0.741$ & a & 0.660 & $0.606,0.714$ & \\
\hline$W C(\mathrm{~cm})$ & 0.727 & $0.671,0.782$ & b & 0.692 & $0.639,0.744$ & $\mathrm{~b}$ \\
\hline TtFM (of TBM) & 0.666 & $0 \cdot 606,0.725$ & a & 0.607 & $0.553,0.661$ & $\mathrm{a}$ \\
\hline AmFM (of TFM) & 0.544 & $0.479,0.610$ & $a, b$ & 0.597 & $0.540,0.655$ & \\
\hline -LgFM (of TFM)§ & 0.633 & $0.571,0.694$ & & $0 \cdot 702$ & $0.650,0.754$ & \\
\hline TrFM (of TFM) & 0.630 & $0.568,0.692$ & & 0.682 & $0.628,0.736$ & \\
\hline RbFM (of TFM) & 0.681 & $0.622,0.740$ & & 0.697 & $0.643,0.750$ & \\
\hline PIFM (of TFM) & 0.573 & $0.509,0.637$ & a & 0.572 & $0.512,0.632$ & $\mathrm{a}$ \\
\hline -SpFM (of TFM)§ & 0.576 & $0.511,0.641$ & a & 0.428 & $0.366,0.489$ & $a, b$ \\
\hline \multicolumn{7}{|c|}{ Dyslipidaemia-HDL-C NCEP component } \\
\hline BMI $\left(\mathrm{kg} / \mathrm{m}^{2}\right)$ & 0.625 & $0.562,0.687$ & & 0.698 & $0.648,0.748$ & \\
\hline WC (cm) & 0.623 & $0.561,0.686$ & & 0.709 & $0.660,0.758$ & $\mathrm{~b}$ \\
\hline TtFM (of TBM) & 0.624 & $0.562,0.686$ & & 0.604 & $0.550,0.657$ & a \\
\hline AmFM (of TFM) & 0.509 & $0.443,0.574$ & $a, b$ & 0.594 & $0.540,0.648$ & a \\
\hline -LgFM (of TFM) & 0.526 & $0.461,0.591$ & & 0.648 & $0.596,0.700$ & \\
\hline TrFM (of TFM) & 0.535 & $0.470,0.600$ & & 0.637 & $0.585,0.690$ & \\
\hline RbFM (of TFM) & 0.598 & $0.533,0.663$ & & 0.675 & $0.625,0.726$ & \\
\hline PIFM (of TFM) & 0.516 & $0.450,0.582$ & & 0.497 & $0.441,0.552$ & $\mathrm{a}$ \\
\hline -SpFM (of TFM)§ & 0.579 & $0.513,0.645$ & & 0.439 & $0.384,0.494$ & a \\
\hline \multicolumn{7}{|l|}{ HOMA-IR $>2 \cdot 61 \|$} \\
\hline $\mathrm{BMI}\left(\mathrm{kg} / \mathrm{m}^{2}\right)$ & $0 \cdot 817$ & $0.770,0.865$ & & $0 \cdot 808$ & $0.765,0.852$ & $\mathrm{~b}$ \\
\hline WC (cm) & $0 \cdot 817$ & $0.767,0.867$ & & 0.818 & $0.776,0.861$ & $\mathrm{~b}$ \\
\hline TtFM (of TBM) & 0.762 & $0.709,0.815$ & & 0.693 & $0.642,0.743$ & $\mathrm{a}$ \\
\hline AmFM (of TFM) & 0.545 & $0.478,0.611$ & $a, b$ & 0.686 & $0.634,0.739$ & $\mathrm{a}$ \\
\hline -LgFM (of TFM)§ & 0.550 & $0.485,0.614$ & $\mathrm{a}, \mathrm{b}$ & 0.674 & $0.621,0.726$ & a \\
\hline TrFM (of TFM) & 0.576 & $0.511,0.641$ & $a, b$ & 0.640 & $0.585,0.695$ & a \\
\hline RbFM (of TFM) & 0.662 & $0.603,0.722$ & a & 0.746 & $0.700,0.794$ & \\
\hline PIFM (of TFM) & 0.517 & $0.450,0.583$ & $a, b$ & 0.504 & $0.445,0.563$ & $a, b$ \\
\hline$-\mathrm{SpFM}$ (of TFM)§ & 0.619 & $0.554,0.684$ & $a, b$ & 0.508 & $0.447,0.568$ & $a, b$ \\
\hline \multicolumn{7}{|c|}{ Uric acid $>6 \mathrm{mg} / \mathrm{dl}$ (women), $>7 \mathrm{mg} / \mathrm{dl}$ (men) } \\
\hline BMI $\left(\mathrm{kg} / \mathrm{m}^{2}\right)$ & 0.699 & $0.628,0.770$ & & $0 \cdot 730$ & $0.664,0.795$ & \\
\hline WC (cm) & 0.658 & $0.580,0.737$ & & 0.763 & $0.703,0.823$ & $\mathrm{~b}$ \\
\hline TtFM (of TBM) & 0.632 & $0.562,0.703$ & & 0.652 & $0.586,0.718$ & $a, b$ \\
\hline
\end{tabular}




\begin{tabular}{|c|c|c|c|c|c|c|}
\hline & \multicolumn{3}{|c|}{ White men ( $n$ 314)‡ } & \multicolumn{3}{|c|}{ White women $(n$ 425) $\ddagger$} \\
\hline & AUC & $95 \% \mathrm{Cl}$ & & AUC & $95 \% \mathrm{Cl}$ & \\
\hline AmFM (of TFM) & 0.451 & $0.371,0.532$ & $\mathrm{a}, \mathrm{b}$ & 0.679 & $0.607,0.752$ & \\
\hline - LqFM (of TFM) & 0.561 & $0.479,0.644$ & & 0.662 & $0.596,0.728$ & \\
\hline TrFM (of TFM) & 0.591 & $0.509,0.673$ & & 0.625 & $0.554,0.695$ & $\mathrm{a}$ \\
\hline RbFM (of TFM) & 0.663 & $0.589,0.736$ & & 0.697 & $0.632,0.763$ & \\
\hline PIFM (of TFM) & 0.569 & $0.488,0.650$ & & 0.556 & $0.481,0.631$ & a \\
\hline -SpFM (of TFM)§ & 0.607 & $0.521,0.693$ & & 0.523 & $0.442,0.604$ & $a, b$ \\
\hline \multicolumn{7}{|l|}{$\mathrm{CRP}>2.11 \mathrm{mg} / \mathrm{l}$} \\
\hline BMI $\left(\mathrm{kg} / \mathrm{m}^{2}\right)$ & 0.641 & $0.575,0.707$ & & $0 \cdot 757$ & $0 \cdot 710,0 \cdot 804$ & \\
\hline WC $(\mathrm{cm})$ & 0.636 & $0.570,0.702$ & & 0.754 & $0.706,0.802$ & \\
\hline TtFM (of TBM) & 0.643 & $0.578,0.708$ & & 0.725 & $0.675,0.775$ & \\
\hline AmFM (of TFM) & 0.500 & $0.432,0.568$ & $a, b$ & 0.654 & $0.601,0.708$ & a \\
\hline - LqFM (of TFM) & 0.441 & $0.373,0.508$ & $a, b$ & 0.621 & $0.566,0.676$ & a \\
\hline TrFM (of TFM) & 0.458 & $0.391,0.526$ & $a, b$ & 0.610 & $0.555,0.665$ & $a, b$ \\
\hline RbFM (of TFM) & 0.508 & $0.440,0.575$ & $a, b$ & 0.682 & $0.630,0.735$ & \\
\hline PIFM (of TFM) & 0.512 & $0.444,0.579$ & a & 0.493 & $0.436,0.550$ & $a, b$ \\
\hline \multirow[t]{3}{*}{-SpFM (of TFM)§ } & 0.622 & $0.557,0.687$ & & 0.495 & $0.438,0.552$ & $\mathrm{a}, \mathrm{b}$ \\
\hline & \multicolumn{3}{|c|}{ African-American men ( $n$ 469) } & \multicolumn{3}{|c|}{ African-American women ( $n$ 611) } \\
\hline & AUC & $95 \% \mathrm{Cl}$ & & $\mathrm{ROC}$ area & $95 \% \mathrm{Cl}$ & \\
\hline \multicolumn{7}{|l|}{ MetS (definition 2) +} \\
\hline BMI $\left(\mathrm{kg} / \mathrm{m}^{2}\right)$ & 0.674 & $0 \cdot 606,0.741$ & & 0.631 & $0.575,0.687$ & $\mathrm{~b}$ \\
\hline WC $(\mathrm{cm})$ & 0.710 & $0.648,0.772$ & & 0.651 & $0.594,0.708$ & $\mathrm{~b}$ \\
\hline TtFM (of TBM) & 0.678 & $0.616,0.739$ & & 0.564 & $0.509,0.618$ & a \\
\hline AmFM (of TFM) & 0.533 & $0.462,0.603$ & $a, b$ & 0.590 & $0.532,0.648$ & \\
\hline -LgFM (of TFM)§ & 0.672 & $0.605,0.738$ & & 0.649 & $0.587,0.710$ & \\
\hline TrFM (of TFM) & 0.669 & $0.605,0.733$ & & 0.637 & $0.576,0.698$ & \\
\hline RbFM (of TFM) & 0.706 & $0.646,0.765$ & & 0.706 & $0.652,0.761$ & $\mathrm{~b}$ \\
\hline PIFM (of TFM) & 0.536 & $0.467,0.605$ & $a, b$ & 0.500 & $0.437,0.563$ & a \\
\hline -SpFM (of TFM) § & 0.533 & $0.462,0.604$ & $a, b$ & 0.504 & $0.437,0.570$ & a \\
\hline \multicolumn{7}{|c|}{ Blood pressure NCEP component† } \\
\hline BMI $\left(\mathrm{kg} / \mathrm{m}^{2}\right)$ & 0.598 & $0.548,0.651$ & & 0.549 & $0.503,0.595$ & \\
\hline WC (cm) & 0.602 & $0.549,0.654$ & & 0.553 & $0.508,0.599$ & \\
\hline TtFM (of TBM) & 0.606 & $0.555,0.657$ & & 0.545 & $0.500,0.591$ & \\
\hline AmFM (of TFM) & 0.536 & $0.482,0.590$ & & 0.520 & $0.474,0.566$ & \\
\hline -LgFM (of TFM)§ & 0.640 & $0.587,0.692$ & & 0.535 & $0.489,0.581$ & \\
\hline TrFM (of TFM) & 0.625 & $0.573,0.678$ & & 0.535 & $0.489,0.581$ & \\
\hline RbFM (of TFM) & 0.606 & $0.554,0.656$ & & 0.561 & $0.516,0.607$ & \\
\hline PIFM (of TFM) & 0.542 & $0.488,0.595$ & & 0.476 & $0.430,0.522$ & \\
\hline$-S p F M($ of TFM) $\$$ & 0.486 & $0.432,0.540$ & a & 0.482 & $0.437,0.529$ & $\mathrm{~b}$ \\
\hline \multicolumn{7}{|c|}{ Fasting qlucose NCEP componentt } \\
\hline $\mathrm{BMI}\left(\mathrm{kg} / \mathrm{m}^{2}\right)$ & 0.710 & $0.651,0.769$ & a & 0.694 & $0.644,0.744$ & $\mathrm{~b}$ \\
\hline WC $(\mathrm{cm})$ & 0.750 & $0.697,0.804$ & & 0.694 & $0.642,0.745$ & \\
\hline TtFM (of TBM) & 0.710 & $0.654,0.766$ & a & 0.637 & $0.587,0.687$ & \\
\hline AmFM (of TFM) & 0.547 & $0.481,0.614$ & $a, b$ & 0.642 & $0.588,0.696$ & \\
\hline -LqFM (of TFM) & 0.602 & $0.535,0.672$ & a & 0.615 & $0.554,0.677$ & \\
\hline TrFM (of TFM) & 0.603 & $0.535,0.671$ & a & 0.591 & $0.530,0.651$ & \\
\hline RbFM (of TFM) & 0.688 & $0.629,0.746$ & & 0.699 & $0.647,0.750$ & \\
\hline PIFM (of TFM) & 0.520 & $0.450,0.589$ & $a, b$ & $0 \cdot 480$ & $0.419,0.542$ & $\mathrm{~b}$ \\
\hline -SpFM (of TFM)§ & 0.596 & $0.530,0.662$ & $a, b$ & 0.514 & $0.449,0.579$ & $\mathrm{~b}$ \\
\hline \multicolumn{7}{|c|}{ Dyslipidaemia-TAG NCEP componentt } \\
\hline BMI $\left(\mathrm{kg} / \mathrm{m}^{2}\right)$ & 0.586 & $0.520,0.653$ & & 0.529 & $0.471,0.586$ & $\mathrm{a}$ \\
\hline WC $(\mathrm{cm})$ & 0.602 & $0.537,0.667$ & & 0.584 & $0.527,0.642$ & $\mathrm{~b}$ \\
\hline TtFM (of TBM) & 0.614 & $0.552,0.676$ & & 0.476 & $0.418,0.534$ & a \\
\hline AmFM (of TFM) & 0.502 & $0.434,0.570$ & & 0.527 & $0.467,0.586$ & \\
\hline -LgFM (of TFM) & 0.621 & $0.557,0.685$ & & 0.681 & $0.624,0.737$ & b \\
\hline TrFM (of TFM) & 0.606 & $0.543,0.669$ & & 0.681 & $0.625,0.736$ & $\mathrm{~b}$ \\
\hline RbFM (of TFM) & 0.622 & $0.561,0.684$ & & 0.679 & $0.623,0.735$ & $a, b$ \\
\hline PIFM (of TFM) & 0.519 & $0.454,0.584$ & & 0.556 & $0.492,0.620$ & \\
\hline -SpFM (of TFM)§ & 0.507 & $0.440,0.573$ & $\mathrm{~b}$ & 0.455 & $0.392,0.518$ & $\mathrm{a}$ \\
\hline \multicolumn{7}{|c|}{ Dyslipidaemia-HDL-C NCEP componentt } \\
\hline BMI $\left(\mathrm{kg} / \mathrm{m}^{2}\right)$ & 0.651 & $0.590,0.712$ & & 0.604 & $0.558,0.650$ & $\mathrm{~b}$ \\
\hline WC $(\mathrm{cm})$ & 0.658 & $0.597,0.719$ & & 0.627 & $0.581,0.673$ & $\mathrm{~b}$ \\
\hline TtFM (of TBM) & 0.646 & $0.587,0.704$ & & 0.547 & $0.500,0.593$ & $\mathrm{a}$ \\
\hline AmFM (of TFM) & 0.524 & $0.460,0.587$ & $a, b$ & 0.571 & $0.524,0.617$ & \\
\hline$-\mathrm{LgFM}$ (of TFM) & 0.575 & $0.512,0.637$ & & 0.584 & $0.538,0.630$ & \\
\hline TrFM (of TFM) & 0.581 & $0.517,0.644$ & & 0.577 & $0.531,0.623$ & \\
\hline RbFM (of TFM) & 0.666 & $0.610,0.721$ & & 0.633 & $0.587,0.678$ & $\mathrm{~b}$ \\
\hline
\end{tabular}


Appendix 2 Continued

\begin{tabular}{|c|c|c|c|c|c|c|}
\hline & \multicolumn{3}{|c|}{ African-American men ( $n$ 469) } & \multicolumn{3}{|c|}{ African-American women ( $n$ 611) } \\
\hline & AUC & $95 \% \mathrm{Cl}$ & & ROC area & $95 \% \mathrm{Cl}$ & \\
\hline PIFM (of TFM) & 0.519 & $0.455,0.583$ & $a, b$ & 0.517 & $0.469,0.564$ & a \\
\hline -SpFM (of TFM)§ & 0.593 & $0.528,0.657$ & & 0.542 & $0.495,0.590$ & a \\
\hline \multicolumn{7}{|l|}{ HOMA-IR $>2 \cdot 61 \|$} \\
\hline BMI $\left(\mathrm{kg} / \mathrm{m}^{2}\right)$ & 0.771 & $0.725,0.817$ & $a, b$ & $0 \cdot 752$ & $0.714,0.790$ & \\
\hline WC $(\mathrm{cm})$ & $0 \cdot 815$ & $0.772,0.857$ & & 0.757 & $0.719,0.796$ & $\mathrm{~b}$ \\
\hline TtFM (of TBM) & 0.787 & $0.742,0.832$ & & 0.677 & $0 \cdot 635,0.720$ & a \\
\hline AmFM (of TFM) & 0.612 & $0.559,0.664$ & $\mathrm{a}, \mathrm{b}$ & 0.666 & $0 \cdot 623,0.710$ & a \\
\hline -LgFM (of TFM) & 0.585 & $0.529,0.642$ & $a, b$ & 0.645 & $0.600,0.689$ & a \\
\hline TrFM (of TFM) & 0.589 & $0.534,0.644$ & $a, b$ & 0.620 & $0.574,0.665$ & a \\
\hline RbFM (of TFM) & $0 \cdot 713$ & $0.665,0.762$ & $a, b$ & 0.727 & $0.687,0.767$ & \\
\hline PIFM (of TFM) & 0.502 & $0.446,0.558$ & $a, b$ & 0.476 & $0.429,0.523$ & $a, b$ \\
\hline -SpFM (of TFM)§ & 0.646 & $0.592,0.699$ & $a, b$ & 0.523 & $0.480,0.574$ & $\mathrm{a}, \mathrm{b}$ \\
\hline \multicolumn{7}{|c|}{ Uric acid $>6 \mathrm{mg} / \mathrm{dl}$ (women), $>7 \mathrm{mg} / \mathrm{dl}$ (men) } \\
\hline BMI $\left(\mathrm{kg} / \mathrm{m}^{2}\right)$ & 0.602 & $0.538,0.665$ & & 0.651 & $0.597,0.705$ & \\
\hline WC $(\mathrm{cm})$ & 0.635 & $0.575,0.694$ & & 0.636 & $0.601,0.706$ & \\
\hline TtFM (of TBM) & $0 \cdot 640$ & $0 \cdot 580,0 \cdot 700$ & & 0.638 & $0.586,0.690$ & \\
\hline AmFM (of TFM) & 0.524 & $0.462,0.586$ & $\mathrm{~b}$ & 0.572 & $0.518,0.626$ & \\
\hline -LgFM (of TFM)§ & 0.582 & $0.521,0.643$ & & 0.564 & $0.507,0.622$ & \\
\hline TrFM (of TFM) & 0.574 & $0.513,0.635$ & & 0.567 & $0.510,0.623$ & \\
\hline RbFM (of TFM) & 0.602 & $0.542,0.663$ & & 0.639 & $0.587,0.691$ & \\
\hline PIFM (of TFM) & 0.496 & $0.433,0.559$ & $a, b$ & 0.501 & $0.449,0.557$ & $a, b$ \\
\hline -SpFM (of TFM)§ & $0 \cdot 491$ & $0.428,0.554$ & $a, b$ & 0.532 & $0.474,0.591$ & $a, b$ \\
\hline \multicolumn{7}{|l|}{$\mathrm{CRP}>2.11 \mathrm{mg} / \mathrm{l}$} \\
\hline BMI $\left(\mathrm{kg} / \mathrm{m}^{2}\right)$ & 0.634 & $0.581,0.687$ & $\mathrm{~b}$ & 0.712 & $0.670,0.754$ & $\mathrm{~b}$ \\
\hline WC $(\mathrm{cm})$ & 0.654 & $0.602,0.707$ & $\mathrm{~b}$ & 0.729 & $0.688,0.770$ & \\
\hline TtFM (of TBM) & 0.687 & $0.636,0.739$ & & 0.700 & $0.657,0.743$ & \\
\hline AmFM (of TFM) & 0.550 & $0.496,0.604$ & $a, b$ & 0.616 & $0.570,0.662$ & a \\
\hline -LgFM (of TFM)§ & 0.561 & $0.506,0.616$ & $\mathrm{~b}$ & 0.634 & $0.589,0.680$ & a \\
\hline TrFM (of TFM) & 0.560 & $0.505,0.614$ & $a, b$ & 0.626 & $0.580,0.672$ & $\mathrm{a}$ \\
\hline RbFM (of TFM) & 0.603 & $0.550,0.656$ & b & 0.644 & $0.598,0.690$ & a \\
\hline PIFM (of TFM) & 0.493 & $0.438,0.548$ & $a, b$ & 0.547 & $0.500,0.595$ & $a, b$ \\
\hline -SpFM (of TFM)§ & 0.515 & $0.461,0.570$ & $a, b$ & 0.485 & $0.447,0.542$ & $a, b$ \\
\hline
\end{tabular}

AUC, area under the receiver-operating characteristic (ROC) curve; MetS, metabolic syndrome; HANDLS, Healthy Aging in Neighborhoods of Diversity Across the Life Span; WC, waist circumference; TtFM; percentage total body fat mass; TBM, total body mass; AmFM, percentage arm fat mass; TFM, total fat mass; LgFM, percentage leg fat mass; TrFM, percentage trunk fat mass; RbFM, percentage rib fat mass; PIFM, percentage pelvic fat mass; SpFM, percentage spine fat mass; NCEP, National Cholesterol Education Program; HDL-C, HDL cholesterol; HOMA-IR, homeostasis model assessment-insulin resistance; CRP, C-reactive protein.

${ }^{\text {a }} \mathrm{P}<0.05$ for the null hypothesis that AUC for a specific test measure is the same as that of the reference measurement (WC, $\mathrm{cm}$ ); Bonferroni adjustment for multiple comparisons was used.

${ }^{\mathrm{b}} \mathrm{P}<0.05$ for the null hypothesis that AUC for a specific test measure is the same as that of the alternative reference measurement (TfFM); Bonferroni adjustment for multiple comparisons was used.

+Using definition 1, MetS was positive when three or more of the following criteria screened as positive. These criteria are derived from the NCEP Adult Treatment Panel III (2001) ${ }^{(1)}$. (i) Central obesity NCEP component: WC $\geq 102 \mathrm{~cm}$ for men and WC $\geq 88 \mathrm{~cm}$ for women; (ii) blood pressure NCEP component: systolic blood pressure/diastolic blood pressure $\geq 130 / 85 \mathrm{mmHg}$; (iii) fasting glucose NCEP component: fasting glucose $\geq 110 \mathrm{mg} / \mathrm{dl}$; (iv) dyslipidaemia-TAG NCEP component: TAG $\geq 150 \mathrm{mg} / \mathrm{dl}$; $(\mathrm{v})$ dyslipidaemia-HDL-C NCEP component: HDL-C $<40 \mathrm{mg} / \mathrm{dl}$ for men and HDL-C $<50 \mathrm{mg} / \mathrm{dl}$ for women. Using definition 2, MetS was positive when two or more of the preceding criteria screened positive excluding criteria (i) and (v).

$\ddagger$ Sample sizes available for each analysis varied depending on metabolic outcome.

§AUC values were obtained based on a ROC curve analysis in which LgFM and SpFM observed values were multiplied by -1

IHOMA-IR is the product of the fasting values of glucose $\left(G_{0}\right.$; expressed as $\left.\mathrm{mg} / \mathrm{dl}\right)$ and insulin $\left(I_{0}\right.$, expressed as $\left.\mu \mathrm{U} / \mathrm{ml}\right)$, divided by a constant: $I_{0} \times G_{0} / 405$. 